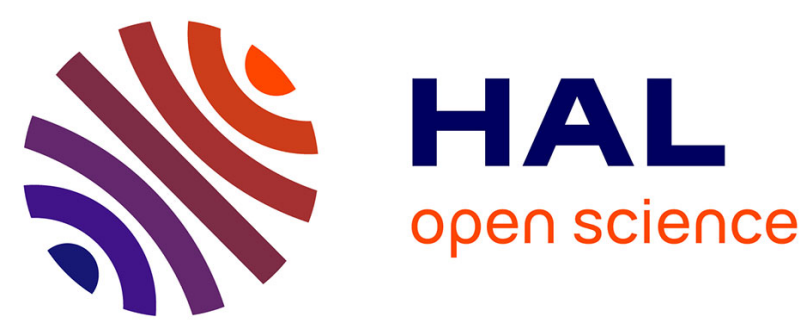

\title{
Chronic treatments with a 5-HT4 receptor agonist decrease amyloid pathology in the entorhinal cortex and learning and memory deficits in the 5xFAD mouse model of Alzheimer's disease
}

Kévin Baranger, Patrizia Giannoni, Stéphane Girard, Sarah Girot, Florence Gaven, Delphine Stephan, Martine Migliorati, Michel Khrestchatisky, Joël Bockaert, Evelyne Marchetti-Gauthier, et al.

\section{- To cite this version:}

Kévin Baranger, Patrizia Giannoni, Stéphane Girard, Sarah Girot, Florence Gaven, et al.. Chronic treatments with a 5-HT4 receptor agonist decrease amyloid pathology in the entorhinal cortex and learning and memory deficits in the 5xFAD mouse model of Alzheimer's disease. Neuropharmacology, 2017, 126, pp.128-141. 10.1016/j.neuropharm.2017.08.031 . hal-01799428

\section{HAL Id: hal-01799428 \\ https://hal.science/hal-01799428}

Submitted on 24 May 2018

HAL is a multi-disciplinary open access archive for the deposit and dissemination of scientific research documents, whether they are published or not. The documents may come from teaching and research institutions in France or abroad, or from public or private research centers.
L'archive ouverte pluridisciplinaire HAL, est destinée au dépôt et à la diffusion de documents scientifiques de niveau recherche, publiés ou non, émanant des établissements d'enseignement et de recherche français ou étrangers, des laboratoires publics ou privés. 


\section{Chronic treatments with a 5-HT 4 receptor agonist decrease amyloid pathology}

in the entorhinal cortex and learning and memory deficits in the $5 x F A D$ mouse model of Alzheimer's disease.

Kevin Baranger ${ }^{\mathrm{a}, 1}$, Patrizia Giannoni ${ }^{\mathrm{b}, \mathrm{c}, 1}$, Stéphane D. Girard ${ }^{\mathrm{a}, \mathrm{d}}$, Sarah Girot ${ }^{\mathrm{a}}$, Florence Gaven ${ }^{\mathrm{b}}$, Delphine Stephan ${ }^{\mathrm{a}}$, Martine Migliorati ${ }^{\mathrm{a}}$, Michel Khrestchatisky ${ }^{\mathrm{a}}$, Joël Bockaert ${ }^{\mathrm{b}}$, Evelyne Marchetti-Gauthiera $^{a}$, Santiago Rivera ${ }^{\mathrm{a}}$, Sylvie Claeysen ${ }^{\mathrm{b},{ }^{*}}$ and François S. Roman, ${ }^{\mathrm{a}, *}$

a. Aix Marseille Univ, CNRS, NICN, Marseille, France.

b. IGF, CNRS, INSERM, Univ. Montpellier, F-34094 Montpellier, France.

1. These authors contributed equally to this work.

c. Present address: Equipe Chrome, EA7352, Université de Nîmes, 30000 Nîmes, France.

d. Present address: Vect-Horus S.A.S., Faculté de Médecine Secteur Nord, CS80011, Boulevard Pierre Dramard, 13344 Marseille Cedex 15, France.

*Corresponding authors: francois.roman@univ-amu.fr and sylvie.claeysen@igf.cnrs.fr

Keywords: 5-HT 4 receptor agonist, Alzheimer's disease, memory impairments, Olfactory Tubing Maze, transgenic mouse model, pharmacotherapy.

\section{Abbreviations}

5-HT ${ }_{4} \mathrm{R}: 5$-Hydroxytryptamine type 4 receptor; $\mathrm{A} \beta$ : Amyloid beta peptide; AD: Alzheimer's Disease; ApoE: Apolipoprotein E; APP: Amyloid beta Precursor Protein; GAPDH: Glyceraldehyde-3-phosphate dehydrogenase; GFAP: Glial Fibrillary Acidic Protein; Iba1: Ionized calcium-binding adapter molecule 1; IHC: immunohistochemistry; IL-1 $\beta$ : interleukin $1 \beta$; ITI: inter-trial interval; i.p.: intraperitoneal 
injection; MCP-1: Monocyte Chemoattractant Protein-1; OTM: Olfactory Tubing Maze; PBS: Phosphate-Buffer Saline; sAPP $\alpha$ : soluble Amyloid beta Precursor Protein $\alpha$; TC: Testing Chamber; ThT: Thioflavin T. 


\section{Abstract}

Alzheimer's disease (AD) is the main cause of dementia and a major health issue worldwide. The complexity of the pathology continues to challenge its comprehension and the implementation of effective treatments. In the last decade, a number of possible targets of intervention have been pointed out, among which the stimulation of $5-\mathrm{HT}_{4}$ receptors $\left(5-\mathrm{HT}_{4} \mathrm{Rs}\right)$ seems very promising. $5-\mathrm{HT}_{4} \mathrm{R}$ agonists exert pro-cognitive effects, inhibit amyloid- $\beta$ peptide $(A \beta)$ production and therefore directly and positively impact $\mathrm{AD}$ progression. In the present work, we investigated the effects of RS 67333, a partial 5-HT 4 R agonist, after chronic administration in the 5xFAD mouse model of AD. 5xFAD male mice and their wild type (WT) male littermates received either RS 67333 or vehicle solution i.p., twice a week, for 2 or 4 months. Cognitive performance was evaluated in a hippocampal-dependent behavioral task, the olfactory tubing maze (OTM). Mice were then sacrificed to evaluate the metabolism of the amyloid precursor protein (APP), amyloidosis and neuroinflammatory processes. No beneficial effects of RS 67333 were observed in $5 \mathrm{xFAD}$ mice after 2 months of treatment, while $5 \mathrm{xFAD}$ mice treated for 4 months showed better cognitive abilities compared to vehicle-treated 5xFAD mice. The beneficial effects of RS 67333 on learning and memory correlated with the decrease in both amyloid plaque load and neuroinflammation, more specifically in the entorhinal cortex. The most significant improvements in learning and memory and reduction of pathology stigmata were observed after the 4-month administration of RS 67333, demonstrating that treatment duration is important to alleviate amyloidosis and glial reactivity, particularly in the entorhinal cortex. These results confirm the $5-\mathrm{HT}_{4} \mathrm{R}$ as a promising target for $\mathrm{AD}$ pathogenesis and highlight the need for further investigations to characterize fully the underlying mechanisms of action. 


\section{Introduction}

Alzheimer's disease (AD) is the most common neurodegenerative disorder that affects elderly people and for which no cure or prevention currently exists. Proteolytic processing of APP and A $\beta$ metabolism is central in $\mathrm{AD}$ pathogenesis (Selkoe and Hardy, 2016). A $\beta$ release mainly involves the sequential proteolytic processing of APP by $\beta$-secretase (BACE-1) and the $\gamma$-secretase complex, but other recently reported proteolytic systems may also account for the cytotoxic cleavage of APP (Baranger et al., 2016a; Baranger et al., 2016b; Willem et al., 2015; Zhang et al., 2015). Non-amyloidogenic APP processing involves the $\alpha$-secretase (A disintegrin and metalloproteinase-10, ADAM10) (Kuhn et al., 2010), which prevents A $\beta$ formation and leads to the release of the neuroprotective N-terminal soluble APP fragment, sAPP $\alpha$ (Nhan et al., 2015).

Previous reports have shown that the activation of G protein-coupled receptors enhances sAPP $\alpha$ production by stimulating $\alpha$-secretase activity. This includes the activation of muscarinic M1-M3 acetylcholine receptors, metabotropic glutamate receptor (mGlu2), serotonin $2 \mathrm{~A}\left(5-\mathrm{HT}_{2 \mathrm{~A}}\right)$, and $2 \mathrm{C}(5-$ $\mathrm{HT}_{2 \mathrm{C}}$ ) receptors (Thathiah and De Strooper, 2011). We, and others, have demonstrated that the activation of serotonin type 4 receptors $\left(5-\mathrm{HT}_{4} \mathrm{R}\right)$ constitutes an increasingly attractive therapeutic strategy against amyloid toxicity in $\mathrm{AD}$. 5-HT 4 R agonists improve the release of sAPP $\alpha$ in vitro and in vivo (Cochet et al., 2013; Maillet et al., 2003), leading to neuroprotective effects associated with the reduction of soluble A $\beta$ levels and amyloid plaques in vivo (Cho and Hu, 2007; Giannoni et al., 2013; Hashimoto et al., 2012; Tesseur et al., 2013). 5-HT $\mathrm{R}$ agonists also ameliorated memory deficits by increasing acetylcholine levels and neurotransmission (Bockaert et al., 2011; Consolo et al., 1994; Johnson et al., 2012). Thus, targeting the $5-\mathrm{HT}_{4} \mathrm{R}$ conveys beneficial effects in $\mathrm{AD}$, both by reducing $\mathrm{A} \beta$ production and by improving learning abilities.

The 5XFAD mouse model provides a rapid evolution of the pathology, which includes early detection of key biomarkers such as amyloid deposition and neuroinflammation, along with cognitive deficits at a prodromal phase of the pathology (around 4 months of age) (Oakley et al., 2006). This mouse model also stands up among the few transgenic AD models that display neuronal death at advanced stages of the disease (beyond 9 months), suggesting the pathological relevance of pathogenic mechanisms set up 
at early time points (i.e., prodromal phase). Altogether, the model recapitulates the main trends of the human pathology and cognitive impairment in a short period of time, which makes it very suitable for testing the protective effects of drugs upon chronic administration. To assess the effectiveness of chronic 5- $\mathrm{HT}_{4} \mathrm{R}$ activation, we chose a therapeutic window spanning through the prodromal phase of the disease in the 5XFAD mice, when the first clinical signs are detected, in order to highlight its possible clinical relevance. Due to the very rapid desensitization of $5-\mathrm{HT}_{4} \mathrm{R}$ in an endogenous neuronal context (Ansanay et al., 1992), we believe that in chronic administration, partial agonists should be preferred to avoid internalization of the target receptor and loss of the desired effect. The chronic administration of the drug was scheduled twice a week in order to prevent desensitization of the system, a schedule that has proved to be efficient in a previous work (Giannoni et al., 2013).

RS 67333 is a partial 5- $\mathrm{HT}_{4} \mathrm{R}$ agonist that has been widely acknowledged for its pro-cognitive effects (Cachard-Chastel et al., 2008; Freret et al., 2012; Marchetti et al., 2004; Marchetti et al., 2000). We have shown that RS 67333 is also a submicromolar acetylcholinesterase (AChE) inhibitor (Lecoutey et al., 2014) and therefore could contribute to restoring altered cholinergic neurotransmission in AD (Herholz et al., 2008). Moreover, we have shown that it can promote the production of sAPP $\alpha$ and prevent early behavioral deficits in the 5xFAD mouse model of AD (Giannoni et al., 2013). Such cognitive improvement is relevant with respect to hippocampal-dependent episodic long-term memory deficits, which are a hallmark of $\mathrm{AD}$ at the beginning of the prodromal phase (Hodges and Patterson, 1995).

To investigate whether chronic administration of RS 67333 could reduce learning and memory deficits associated with the hippocampus during the prodromal phase of the pathology, 5xFAD mice were tested in the olfactory tubing maze (OTM). We have previously used this behavioral task to demonstrate that selective bilateral lesions of the hippocampus in rodents induce specific impairments in declarative memory, while sparing non-declarative memory (Chaillan et al., 2005; Squire and Wixted, 2011), which is also the case during the prodromal AD in humans (Pike et al., 2007). Moreover, trained mice assessed in the OTM display increased spine density in the pyramidal neurons of the CA1 hippocampal region and administration of the $5-\mathrm{HT}_{4} \mathrm{R}$ partial agonist SL65.0155 prior training 
potentiates the spine density related to an improvement in learning and memory performance (Chaillan et al., 2005; Restivo et al., 2006a; Restivo et al., 2008; Restivo et al., 2006b). In the present study, we found that RS 67333 treatment over a 4-month period, spanning from the asymptomatic to the symptomatic phases, significantly decreased the specific impairments related to declarative memory in 5xFAD mice. These pro-mnesic effects of RS 67333 were associated with reductions in amyloid plaque load, glial reactivity and the levels of inflammatory mediators, specifically in the entorhinal cortex. Taken together, these data support the growing interest in $5-\mathrm{HT}_{4} \mathrm{R}$ agonists as a potential treatment for $\mathrm{AD}$. 


\section{Methods}

\subsection{Animals}

All the experimental procedures were conducted on male mice in accordance with National and European regulations (EU directive $\mathrm{N}^{\circ} 2010 / 63$ ), and in agreement with the authorization for animal experimentation attributed to the laboratory by the Prefecture des Bouches-du-Rhône (permit number: D 13055 08). All efforts were made to minimize animal suffering and to reduce the number of mice used. The generation of transgenic 5xFAD mice has been described previously (Oakley et al., 2006). These mice carry mutations in both human amyloid precursor protein $\left(A P P_{695}\right)$ and presenilin-1 (PSEN1) genes. The APP gene harbors three Familial Alzheimer's Disease (FAD) mutations: Swedish (K670N, M671L), Florida (I716V), and London (V717I). The human PSEN1 gene harbors two FAD mutations: M146L and L286V. Human gene expression is regulated by neural-specific elements of the mouse Thy1 promoter to drive neuronal specificity. The $5 \mathrm{xFAD}$ strain (B6/SJL genetic background) was maintained by crossing heterozygous transgenic mice with B6/SJL F1 breeders (Jackson Laboratories, Bar Harbor, Maine, USA). 5xFAD heterozygous transgenic mice were used for the experiments with WT littermates as controls. Genomic DNA was extracted from mice tail tips to assess their genotype by PCR. All transgenic and WT mice were bred in our animal facility, had access to food and water ad libitum, and were housed under a $12 \mathrm{~h}$ light-dark cycle $(12 \mathrm{~h}-12 \mathrm{~h})$ at $22-24^{\circ} \mathrm{C}$. During the OTM habituation and training periods, mice were placed on water restriction, while ensuring that their body weight was maintained at approximately $80 \%$ of its initial value during the training sessions. Behavioral testing, immunohistochemistry (IHC) and biochemistry analyses were sequentially performed on 5xFAD male mice and their respective WT littermates at 4 and 6 months of age, corresponding to the prodromal and symptomatic phases of the pathology, respectively (Giannoni et al., 2013; Py et al., 2014).

\subsection{Drugs and animal treatments}

RS 67333 (1-(4-amino-5-chloro-2-methoxy-phenyl)-3-(1-butyl-4-piperidinyl)-1-propa-none)) was purchased from Tocris Bioscience (R\&D Systems Europe, Lille, France), resuspended in DMSO (37.5 $\mu \mathrm{g} / \mu \mathrm{l}$, stored at $-20^{\circ} \mathrm{C}$ ) and freshly diluted $1: 250$ in $0.9 \% \mathrm{NaCl}$ prior administration. Two-month-old 
5xFAD mice and their WT littermates received either RS $67333(1 \mathrm{mg} / \mathrm{kg})$ or vehicle solution $(0.9 \%$ $\mathrm{NaCl}, 0.4 \%$ DMSO) i.p., twice a week, for 2 (protocol 1) or 4 months (protocol 2). Mice were tested for learning and memory in the OTM (see below), and then sacrificed at 4 and 6 months of age according to protocols 1 and 2, respectively (Fig. 2A). Eight mice per group were used in protocol 1 and seven per group in protocol 2. Mice were anesthetized with sodium pentobarbital and transcardially perfused with $\mathrm{NaCl} 0.9 \%$. Brains were extracted and separated into two parts. One part was further used for microdissection of the entorhinal cortex and the other was post-fixed overnight in cold $4 \%$ paraformaldehyde, then washed and stored in PBS at $4^{\circ} \mathrm{C}$.

\subsection{Western blot biochemical analysis}

APP fragments, A $\beta$ and Glial Fibrillary Acidic Protein (GFAP) protein levels in the entorhinal cortex were analyzed by western blot as previously described (Baranger et al., 2016b). Briefly, dissected entorhinal cortices were homogenized in $25 \% \mathrm{w} / \mathrm{v}$ of $50 \mathrm{mM}$ Tris-HCl, $\mathrm{pH} 7.5$ buffer containing 150 $\mathrm{mM} \mathrm{NaCl}, 2 \mathrm{mM}$ EDTA, 1\% Triton X-100, 0.05\% SDS and proteinase inhibitor cocktail (Millipore) and centrifuged at $10,000 \mathrm{x} g$ for $10 \mathrm{~min}$ at $4^{\circ} \mathrm{C}$. This "soluble fraction" contained cytosolic proteins and proteins easy to solubilize. Cell pellets were resuspended in $25 \% \mathrm{w} / \mathrm{v}$ of $50 \mathrm{mM}$ Tris- $\mathrm{HCl} \mathrm{pH} 7.5 \mathrm{buffer}$ containing $2 \% \mathrm{SDS}$, then sonicated and centrifuged at $10,000 \mathrm{xg}$ for $10 \mathrm{~min}$ at $4^{\circ} \mathrm{C}$ to obtain an "insoluble fraction" containing more insoluble proteins. Protein concentrations were determined using a Bio-Rad $D C^{\mathrm{TM}}$ protein assay kit (Bio-Rad, Marnes-La-Coquette, France) and $50 \mu \mathrm{g}$ of protein were run on 10\% SDS-PAGE or on Tris-tricine gels and transferred to nitrocellulose membranes (Amersham Bioscience, Velizy-Villacoublay, France). After blocking, membranes were probed with the following antibodies: anti-APP 22C11 (Millipore), anti-GFAP (1/1000, Millipore), anti-A $\beta$ 6E10 (1/300, Ozyme), anti-APP C-terminal fragment (APP-CTF, 1/1000, Sigma-Aldrich), anti-GAPDH (1/5000, Millipore) and anti-actin (1/5000, Sigma-Aldrich) and then incubated with the appropriate horseradish peroxidaseconjugated secondary IgG antibodies (Jackson Immunoresearch, West Grove, PA, USA). Immunoblot signals were visualized using the ECL chemiluminescence kit (GE Healthcare, Dutscher, Brumath, France) and quantified using ImageJ software.

\subsection{ELISA assays}


The levels of pro-inflammatory mediators IL- $1 \beta$ and MCP-1 were determined in Triton-soluble fractions using the murine ELISA Development Kit (Peprotech, Neuilly-sur-Seine, France), according to the manufacturer's recommendations.

\subsection{Immunohistochemistry}

Thirty-micrometer-thick sections of mouse brains were generated with a vibratome (Microm HM 650 V, Thermo Scientific, Saint Herblain, France) and stored in a cryoprotectant medium (phosphate buffer $0.5 \mathrm{M} \mathrm{pH} 7.4,40 \%$, ethylene glycol $30 \%$ and glycerol $30 \%$ ) at $-20^{\circ} \mathrm{C}$. Amyloid plaques were labeled on free-floating coronal brain sections from frontal, median and caudal positions. The frontal cortex, hippocampus and entorhinal cortex were analyzed as representative brain areas of 5xFAD mice, which, as in humans, are affected early by $\mathrm{AD}$ and are highly enriched in amyloid deposits (Braak and Braak, 1991; Rowe and Villemagne, 2013). The antero-posterior coordinates relative to bregma were: $1.98 \mathrm{~mm}$ (frontal cortex); -1.94 mm (hippocampus); -2.79 mm (entorhinal cortex). Selected sections were extensively washed in PBS and then incubated in a blocking solution (PBS containing 3\% BSA and $0.1 \%$ Triton X-100) for $1 \mathrm{~h}$. Sections were stained first with Hoechst dye (1:1000, Life Technologies, Saint Aubin, France) for 15 min to detect cell nuclei and then with freshly prepared thioflavin T solution (ThT, Sigma-Aldrich; final concentration: $0.01 \mathrm{mg} / \mathrm{mL}$ in the blocking solution) for $15 \mathrm{~min}$. After washing with ethanol $70 \%$ for $5 \mathrm{~min}$, samples were mounted on poly-L-lysine slides with coverslips. For the staining of GFAP and Iba1 (ionized calcium-binding adapter molecule 1), free-floating brain sections were blocked as described and incubated with polyclonal rabbit anti-GFAP (1:1000, Dakocytomation, Les Ullis, France) or polyclonal rabbit anti-Ibal antibody (1:300, Wako, Sobioda, Montbonnot-Saint-Martin, France) and mouse monoclonal 6E10 antibody (1:500, Covance, Ozyme, Saint Quentin en Yvelines). The secondary Alexafluor® 594 goat anti-rabbit antibody and Alexafluor® 488 goat anti-mouse antibody (1:1000, Life Technologies, Saint Aubin, France) were added for $2 \mathrm{~h}$. After PBS washes, slices were mounted as previously described (Giannoni et al., 2013).

\subsection{Image acquisition and analysis}


Images were acquired with an AxioImager Z1 microscope (Carl Zeiss S.A.S., Marly le Roi, France), and blindly analyzed using the ImageJ software. Quantification of amyloid plaques (ThT staining) was represented as the mean number of plaques per $\mathrm{mm}^{2}$. GFAP and Iba1 immunostainings were quantified in the entorhinal cortex and the results expressed as area fractions. For all measurements, final data were the average of two tissue sections from the same brain area per mouse. Representative images of ThT, GFAP and Iba1 staining were taken using a $4 x$ objective. Detailed images of plaques were captured with a $40 x$ objective and selected $Z$-stacks were pooled.

\subsection{Olfactory tubing maze (OTM)}

\subsubsection{Principle}

The OTM experiments were performed as previously described (Girard et al., 2016; Girard et al., 2014; Jourquin et al., 2005; Restivo et al., 2006b; Roman et al., 2002), with specific modifications. The maze is designed to test the ability of mice placed on water restriction to learn odor-reward associations. Training takes place in a testing chamber (TC) connected to two lateral arms, which simultaneously deliver two synthetic odors arbitrarily associated with either a drop of water (the reward) or a nonaversive, but unpleasant buzzing sound, depending on the arm chosen by the mice (Fig. 1).

\subsubsection{Apparatus and learning procedure}

The olfactory tubing maze is composed of four TCs joined to each other by plastic elbow tubes extended on each side by a straight plastic tube (Fig. 1). Mice move freely along the maze in a clockwise direction imposed by the successive automatic opening and closing of the gates at the entrance and exit of the TCs. The odors, the water drop and the buzzing sound are automatically delivered at the end of the lateral arms. The TCs are equipped with two exhaust fan devices that enable the rapid and homogeneous distribution of odors, and their quick ventilation once the mouse quits the TC. Mice movements are detected when they interrupt with an infrared beam generated by a photoelectric cell at the end of the lateral arms. Beam interruption triggers the delivery of water or the buzzing sound, depending on the odor chosen by the mouse. The entire automated procedure and data collection are controlled by a computer and the LabVIEW software (National Instruments France, Nanterre, France). The 
experimenter runs the computer in an adjacent room. Mice perform the test in the dark and can be observed with an infrared camera. The learning procedure consisted of three habituation days followed by seven training days. Each daily session of 12 trials is the result of three entire clockwise laps around the OTM composed of four TCs.

\subsubsection{Behavior analysis}

Three parameters were examined: the percentage of correct responses, the inter-trial interval (ITI) and the number of backtracks:

- The percentage of correct responses was the ratio of the number of correct responses to the total number of odor presentations per session. This is a measure of the efficiency of the association between an odor and its reinforcement, a process that falls within the subcategory of hippocampus-dependent declarative memory when an animal performs the task with two simultaneous odors.

- The ITI was calculated as the time elapsed between the response of the mouse to an odor presentation in one TC and its response in the next TC knowing that the minimum ITI was set at $15 \mathrm{sec}$. The evolution of the ITI reflects the procedural aspect of the task whereby a mouse must learn that following a correct or incorrect response to an odor it has to move on to the next TC, and wait for the gate to open to proceed with the next trial. The mean cumulative time was the mean time elapsed between all the successive trials minus the fixed $15 \mathrm{~s}$ ITI.

- The number of backtracks evaluated the orientation capacity of mice in time and space. After a response (correct or wrong) in a TC, the mouse can go ahead towards the next TC (clockwise direction) and try again to get the reward or make a U-turn towards the previous TC (counterclockwise direction) in which it is no longer possible to make a choice and get a reward (Fig. 1). This is a particularly relevant parameter because spatio-temporal disorientation is a hallmark of $\mathrm{AD}$ related to the degeneration of the hippocampus and its associated structures (Giannakopoulos et al., 2000). Consequently, attempts by mice to move in a counterclockwise direction may reveal a dysfunction of the temporal lobe.

\subsection{Statistical analysis}


Amyloid plaques and gliosis were quantified using two-way ANOVA, followed by a post-hoc Bonferroni's test for multiple comparisons (Prism 6.0f, GraphPad Software, La Jolla, United States) while behavioral differences between groups were tested with repeated-measures (MANOVAs) across sessions, using the SPSS/PC+ statistics software (SPSS, Chicago, United States). All the paired group comparisons were processed by Student's $t$-test. Protein quantification by western blot and ELISA was determined by a one-way ANOVA, followed by post-hoc Fisher's LSD for multiple comparisons (Prism Software). The $p$ levels $(\mathrm{p}<0.05, \mathrm{p}<0.01$ and $\mathrm{p}<0.001)$ in the figures are denoted by asterisks $(*, * *$ and ***, respectively). 


\section{Results}

\subsection{Effects of RS 67333 on amyloid plaques}

We have previously shown that RS 67333 administration has positive effects on APP metabolism by reducing $\mathrm{A} \beta$ levels while increasing sAPP $\alpha$ production in 5xFAD female mice (Giannoni et al., 2013). In the current study, we studied the effects of RS 67333 administration in 5xFAD male mice during 2 (protocol 1) or 4 months (protocol 2) in three brain areas affected in AD: the frontal cortex, hippocampus and entorhinal cortex (Fig. 2A). We observed that chronic RS 67333 treatment induced a significant decrease in the amyloid load only in the entorhinal cortex, as shown by ThT staining (Fig. 2B c,f). These significant reductions were of $31 \%$ and $33 \%$ following protocols 1 and 2 , respectively $(\mathrm{p}<0.05$ ) (Fig. 2E). No significant differences were observed in the frontal cortex or in the hippocampus following protocols 1 and 2 (Fig. 2B a,b,d,e, C and D). While the number of amyloid plaques did not significantly increase between 4 and 6 months in the frontal cortex or entorhinal cortex, we observed a two-fold significant increase $(p<0.001)$ in the amyloid load in the hippocampus (Fig. 2D).

\subsection{Effects of RS 67333 on glial reactivity}

Glial cells, e.g. astrocytes and microglial cells may have beneficial and/or detrimental effects on AD pathogenesis (Ben Haim et al., 2015; Li et al., 2014). They promote neuroinflammatory processes through the release of inflammatory mediators, but are also important for $\mathrm{A} \beta$ homeostasis because they produce A $\beta$-degrading proteinases (Baranger et al., 2014; De Strooper, 2010; Wyss-Coray et al., 2003). In $\mathrm{AD}$ mouse models, glial reactivity is often associated with detrimental processes (Bachstetter et al., 2012; Baranger et al., 2016b; Kitazawa et al., 2011; Wyss-Coray and Rogers, 2012). In our experimental conditions, astroglial reactivity (GFAP staining) was significantly decreased by $61 \%$ in the entorhinal cortex of $5 \mathrm{xFAD}$ mice following protocol 2 , compared to vehicle-injected $5 \mathrm{xFAD}$ mice $(\mathrm{p}<0.01)$. Conversely, protocol 1 did not significantly affect glial reactivity, although a decreasing tendency was observed (Fig. 3A and B). A significant increase of GFAP ${ }^{+}$staining $(\mathrm{p}<0.001)$ was observed between 4 and 6 months of age in the vehicle control group. Similar results were obtained with Iba1 staining, only the longer RS 67333 treatment induced a significant decrease of 59\% in the entorhinal cortex of 5xFAD 
compared to the vehicle control group $(\mathrm{p}<0.05)\left(\right.$ Fig. $3 \mathrm{C}$ and D). Again, a significant increase of Iba1 ${ }^{+}$ staining $(\mathrm{p}<0.001)$ was observed between 4 and 6 months of age in the vehicle control group. GFAP levels were significantly decreased in the Triton-soluble fraction following RS 67333 treatment at 4 and 6 months (Fig. 3E and F). No changes in Iba1 levels were detected in our experimental conditions (data not shown). We also measured the content of two key inflammatory mediators in AD, IL-1 $\beta$ and MCP1 (Heneka et al., 2015). In line with the reduction in glial reactivity, a significant 25 and $30 \%$ decrease in IL-1 $\beta$ and MCP-1, respectively, was observed following protocol 2, compared to vehicle-injected $5 \mathrm{xFAD}$ mice $(\mathrm{p}<0.05)$. No changes were observed following protocol 1 , compared to vehicle-injected 5xFAD mice (Fig. 3G and H). The treatment with RS 67333 strongly reduced the IL-1 $\beta$ and MCP-1 levels by 33 and $45 \%$, respectively, in the 4 -month treated $5 x F A D$ mice compared to the 2 -month treated mice $(\mathrm{p}<0.01)$ (Fig. $3 \mathrm{G}$ and $\mathrm{H})$.

\subsection{Effects of RS 67333 on APP metabolism}

We investigated whether the decrease in the amyloid plaque content following a 4-month treatment with RS 67333 was accompanied by changes in APP/A $\beta$ metabolism. First, soluble APP (sAPP) fragments were detected in the Triton-soluble fraction using the $22 \mathrm{C} 11$ and $6 \mathrm{E} 10$ antibodies, which recognize the N-terminal domain of APP and an epitope in the human A $\beta$ sequence, respectively. A significant increase in the total canonical $22 \mathrm{C} 1^{+}$APP fragments was observed following protocol 2, compared to vehicle-injected $5 \mathrm{xFAD}$ mice $(\mathrm{p}<0.01)$ and mice treated with protocol 1 . No significant changes in $6 \mathrm{E} 10^{+}$fragments were observed (Fig. 4A). Because the $6 \mathrm{E} 10$ antibody recognizes an epitope in the Nterminal domain of the $A \beta$ sequence, we assumed that this antibody detected sAPP $\alpha$ among the high molecular weight soluble fragments of APP. Then, we evaluated the possible changes in the C-terminal APP fragments and A $\beta$ levels in the insoluble fraction, where they were mainly detected. $\beta C T F$ and $\alpha \mathrm{CTF}$ species are respectively produced following $\beta$ - (BACE-1) and $\alpha$-secretase (ADAM-10) processing of APP, respectively, and detected by the APP-CTF antibody, which recognizes the C-terminal domain of APP. No significant changes in $\beta \mathrm{CTF}$ and $\alpha \mathrm{CTF}$ levels were observed in our conditions (Fig. 4B). The $A \beta$ peptide is produced following $\beta C T F$ processing by the $\gamma$-secretase complex. A significant drop 
in $\mathrm{A} \beta$ levels of $70 \%$ was observed following protocol 2, compared to vehicle-injected 5xFAD mice (Fig. 4B). Protocol 1 did not modify A $\beta$ levels (Fig. 4B).

\subsection{Effects of RS 67333 on learning and memory in the OTM}

Vehicle-injected 4-month-old WT mice from protocol 1 were able to learn the odor-reward associations, reaching a score of $70 \%$ of correct responses in session 7 . No statistically significant differences were observed between $5 \mathrm{xFAD}$ and WT mice treated with vehicle, although $5 \mathrm{xFAD}$ mice performed at a slightly lower level throughout the sessions (Fig. 5A). Similarly, there were no significant differences after protocol 1 when comparing: i) WT mice treated with vehicle or RS 67333 (Fig. 5B); ii) 5xFAD mice treated with vehicle or RS 67333 (Fig. 5C); iii) WT and 5xFAD mice, both treated with RS 67333 (Fig. 5D). Consequently, the comparisons between the different paired groups revealed no significant statistical differences across the last three sessions (sessions 5, 6, 7), when significant odor-rewards were consistently made (MANOVA: F(2,28) $\leq 0.57$; NS). No group effect was evidenced either (MANOVA: $\mathrm{F}(1,14) \leq 3.2$; NS). Similarly, no significant differences were observed during the last three sessions between the paired groups considering the cumulative time (Fig. 5E-H) (MANOVA: F(2,28) $\leq 2.62$; NS), with no group difference (MANOVA: $F(1,14) \leq 4.4$; NS). Only transient differences in the cumulative time were observed between: i) WT and 5xFAD mice treated with vehicle during the first session $(\mathrm{t}=2.63 ; \mathrm{p}<0.05)$ (Fig. 5E); ii) WT mice treated with vehicle or RS 67333 in sessions 5 and $7(\mathrm{t}=2.14$; $\mathrm{p}<0.05$ ) (Fig. 5F); 5xFAD mice treated with vehicle or RS 67333 in session $5(\mathrm{t}=-2.61 ; \mathrm{p}<0.05)$ (Fig. 5G). Conversely, at 4 months of age, 5xFAD mice showed a significant difference in the number of backtracks during the last three sessions in comparison with their respective WT vehicle-injected control mice (MANOVA: $F(2,28)=6.94 ; p<0.01$ ), with no group effect (MANOVA: $F(1,14)=2.95$; NS) (Fig. 5I). This unsuited behavior was particularly obvious during sessions 5 and $6[(\mathrm{t}=-2.34 ; \mathrm{p}<0.05)$ and $(\mathrm{t}=-$ $2.20 ; \mathrm{p}<0.05$ ), respectively]. Such differences were not observed across the last three sessions between WT vehicle and WT RS 67333 treated groups (MANOVA: $F(2,28)=6.94 ; p<0.01$ ), but a group difference was present across the sessions (MANOVA: $\mathrm{F}(1,14)=7.22 ; \mathrm{p}<0.05)$ and significant in session $5(\mathrm{t}=-2.15 ; \mathrm{p}<0.05)$ (Fig. 5J). Conversely, no differences were observed between 5xFAD vehicle and 
5xFAD RS 67333 treated groups (Fig. 5K) and between WT and 5xFAD RS 67333-treated groups (Fig. 5L) (MANOVA: $F(3,42) \leq 1.4$; NS), with no group difference (MANOVA: $F(1,14) \leq 0.32$; NS).

In agreement with a recent report (Girard et al., 2014), we observed a significant difference in the percentage of correct responses in 6-month-old mice between vehicle-injected WT and 5xFAD mice (Fig. 6A). Vehicle-injected 5xFAD mice reached only $61 \%$ of correct cue-reward associations after seven training sessions, while vehicle-injected WT mice reached a level of $78 \%$. No significant differences were observed across the last three sessions (session 5,6,7) between the two groups (MANOVA: $\mathrm{F}(2,24)=0.12 ; \mathrm{NS}$ ), but a subsequent group impairment appeared (MANOVA: $F(1,12)=11.13 ; p<0.01)$. This difference was mainly due to sessions five $(t=3.62 ; p<0.01)$ and seven $(\mathrm{t}=3.17 ; \mathrm{p}<0.01$ ). WT RS 67333 groups, treated according to protocol 2 (Fig. 6B), performed at the same level in comparison to their respective controls (WT vehicle) with no difference across the last three sessions (MANOVA: $F(2,24)=0.75$; NS) or group effect (MANOVA: $F(1,12)=0.01$; NS). On the contrary, a significant group difference appeared between 5xFAD vehicle and 5xFAD RS 67333 treated groups (Fig. $6 \mathrm{C}$ ), in the last three sessions (MANOVA: $\mathrm{F}(1,12)=6.64 ; \mathrm{p}<0.05$ ) with no group X session difference (MANOVA: $\mathrm{F}(2,24)=0.5$; NS). This effect was mainly due to a significant difference in session 5, when 5xFAD mice treated with RS 67333 increased their percentage of correct responses by $20 \%$ in comparison to the $5 \mathrm{xFAD}$ vehicle group $(\mathrm{t}=-3.29 ; \mathrm{p}<0.01)$. Such a difference was not observed between WT RS 67333 and 5xFAD RS 67333 treated groups across sessions (MANOVA: F(2,24)=0.66; NS) and between these groups (MANOVA: $\mathrm{F}(1,12)=0.11 ; \mathrm{NS})$ except in session $3(\mathrm{t}=3.11 ; \mathrm{p}<0.01)$ (Fig. 6D). The cumulative time decreased from session to session for all the groups. No significant differences were observed between WT and 5xFAD vehicle groups, except in session $2(\mathrm{t}=2.72 ; \mathrm{p}<0.05)$ (Fig. 6E). RS 67333 had no particular effect on WT mice (Fig. 6F). RS 67333 treatment only elicited an effect in session 1 in $5 x F A D$ mice $(t=-2.22 ; \mathrm{p}<0.05)$ (Fig. 6G). No significant differences were observed between WT and 5xFAD RS 67333-treated groups (Fig. 6H) (MANOVA: $\mathrm{F}(2,24) \leq 0.39$; NS) with no group effect (MANOVA: $\mathrm{F}(1,12) \leq 1.29$; NS). Only a transient difference was observed between 5xFAD and $5 \times$ FAD RS 67333 treated groups during the first $(t=-2.52 ; \mathrm{p}<0.05)$; third $(\mathrm{t}=2.66 ; \mathrm{p}<0.05)$ and fourth $(\mathrm{t}=3.24 ; \mathrm{p}<0.05)$ sessions. 
A statistically significant increase in the number of backtracks was observed in 6-month-old 5xFAD mice in comparison to their respective vehicle-injected WT control (Fig. 6I) during the last three sessions (MANOVA: $F(1,12)=4.84 ; \mathrm{p}<0.05$ ), but not across sessions (MANOVA: $F(2,24)=2.75$; NS). This increase was particularly significant in sessions $6(t=-2.37 ; \mathrm{p}<0.05), 7(\mathrm{t}=-2.85 ; \mathrm{p}<0.05)$, and 2 $(\mathrm{t}=2.27 ; \mathrm{p}<0.05)$. The chronic treatment with $\mathrm{RS} 67333$ had not effect compared to the chronic administration of vehicle in WT mice throughout the sessions (MANOVA: $\mathrm{F}(2,24)=0.31$; NS) with no group effect (MANOVA:F(1,12)=0.15; NS) (Fig. 6J). No significant difference between 5xFAD vehicle and 5xFAD RS 67333-treated groups was observed either in the last three sessions between groups (MANOVA: $F(1,12)=2.75$; NS) or across sessions (MANOVA: $F(2,24)=0.84$; NS) (Fig. 6K), although a significant level was reached in session $4(t=2.76 ; p<0.05)$. The increase in the number of backtracks in the $5 \mathrm{xFAD}$ vehicle group compared to the WT vehicle group (Fig. 6I) disappeared across sessions when the 5xFAD group was treated with RS 67333 (MANOVA: $F(2,24)=0.14$; NS) (Fig. 6L), with no group difference (MANOVA: $\mathrm{F}(1,12)=0.70$; NS) except at the start of the training session $1(\mathrm{t}=-2.17$; $\mathrm{p}<0.05)$. 


\section{Discussion}

5xFAD mice represent an early-onset model of $\mathrm{AD}$, displaying amyloid plaques and glial reactivity at early stages of the pathology, mainly in deep cortical layers and in the subiculum of the hippocampus (Baranger et al., 2016b; Giannoni et al., 2016; Giannoni et al., 2013; Girard et al., 2014; Oakley et al., 2006; Py et al., 2014). In a previous work, we demonstrated the therapeutic efficiency of a 2-month administration of RS 67333 in female 5xFAD mice between 2 and 4 months of age (Giannoni et al., 2013), which is a protocol similar to protocol 1 used in the present study. In the former study, the prevention of cognitive deficits by RS 67333 in the new object recognition test was associated with a decrease in the $\mathrm{A} \beta$ burden and glial reactivity in the frontal and entorhinal cortices, while these parameters were not affected by the 5- $\mathrm{HT}_{4} \mathrm{R}$ agonist in the hippocampus (Giannoni et al., 2013). Here, we describe that two RS 67333 treatments of different duration (protocol 1 and protocol 2, see Fig. 1A) in male 5xFAD mice, induced a decrease in the amyloid plaque load only in the entorhinal cortex, but not in the frontal cortex and hippocampus. Such a decrease in the entorhinal cortex was associated with a drop in GFAP and Ibal staining only in protocol 2, suggesting that the duration of the treatment is crucial to obtain a beneficial impact on $\mathrm{AD}$ stigmata. It has been well demonstrated that $\mathrm{A} \beta$ production impairs hippocampal synaptic plasticity and behavior (Selkoe, 2008; Walsh et al., 2002). Moreover, the amyloid load in the cortex and hippocampus may affect the synaptic transmission between these regions in 5xFAD mice (Baranger et al., 2016b; Crouzin et al., 2013). Here, we confirm that 4-month-old 5xFAD male mice present weak learning and memory deficits in the OTM compared to WT. In contrast, cognitive deficits were more clearly observed at 6 months of age. In this context, RS 67333 only improved learning and long-term declarative-like memory in 6-month-old 5xFAD mice after a 4-month treatment. The treatment used in both protocols increased the ITIs, at least at the beginning of the training, which could be related to the impulsivity observed in 5xFAD mice and thus explain the recovery of learning and memory performance. It is noteworthy that the beneficial effects of RS 67333 on learning and memory correlated with the decrease in both amyloid plaque load and glial reactivity.

In a previous study focused on the onset of hippocampal-dependent memory deficits as a hallmark of prodromal AD (Girard et al., 2014), we described early OTM dysfunctions starting at 4 
months of age and being consolidated at 6 months, in the absence of olfactory impairments per se. These results were further confirmed in a recently published work that revealed no deficits in the ability of 5xFAD male mice to detect odors (Roddick et al., 2016). Although no acquisition deficits were observed in 4-month-old 5xFAD mice in our previous study, we were able to identify an incipient memory deficit at this age. This was illustrated by a greater between-day forgetting of the previous learning (Girard et al., 2014). Similarly, in the present study, no acquisition deficits were observed at 4 months, but early disturbance in learning and memory was revealed by significantly more backtracks in 5xFAD mice compared to WT, possibly reflecting the onset of a spatio-temporal disorientation, similar to that observed in AD patients (Giannakopoulos et al., 2000). This early deficit was worse at 6 months of age, as illustrated by the difficulties of $5 \mathrm{xFAD}$ mice in consistently learning cue-reward associations, compared to the WT control group. Chronic treatment with RS 67333, for 2 or 4 months starting at 2 months of age, prevented learning and memory deficits associated with the hippocampus in $5 \mathrm{xFAD}$ mice. However, the RS 67333 treatment did not affect WT mice, even if during sessions 2 and 3 in the OTM, treated WT mice showed a tendency to perform better than untreated WT mice in the two protocols studied. Numerous studies have documented the pro-cognitive effects of 5-HT $\mathrm{H}_{4}$ agonists on the learning and memory of rodents and macaques in the context of aging-related (Letty et al., 1997; Marchetti-Gauthier et al., 1997; Marchetti et al., 2011; Terry et al., 1998) or pharmacologically-induced (Fontana et al., 1997; Lo et al., 2014) cognitive deficits, as well as in healthy conditions (Lecoutey et al., 2014).

Our data confirm a spatio-temporal correlation between amyloidosis and gliosis in the entorhinal cortex and cognitive deficits. Moreover, the protective effects of RS 67333 seem to be particularly efficient in the entorhinal cortex, where the drug was able to reduce significantly the plaque load, gliosis and levels of inflammatory mediators. As the entorhinal cortex is one of the areas early impacted by AD pathology (Du et al., 2001; Khan et al., 2014; Oakley et al., 2006; Velayudhan et al., 2013), we first hypothesized that a certain level of amyloid deposits was required to demonstrate an effect of our treatments. However, this hypothesis is not consistent with the finding that other structures with similar amyloid loads at 6 months did not benefit from the effects of RS 67333 (Fig. 2B). As an alternative, we are keen to consider the possibility of a selective action of the compound in the entorhinal cortex, based, 
for instance, on a particular subcellular distribution of $5-\mathrm{HT}_{4} \mathrm{R}$ in this region compared to the hippocampus. Overall 5- $\mathrm{HT}_{4} \mathrm{R}$ densities are higher in the hippocampus than in cortical areas in rodents (Manuel-Apolinar et al., 2005) and in humans (Reynolds et al., 1995; Varnas et al., 2003), thus the level of receptors is unlikely to explain the more pronounced effect of RS 67333 in the entorhinal cortex. Despite this apparently significant action restricted to the entorhinal cortex, we observed a preservation of cognitive function in the OTM, a hippocampus-dependent olfactory task (Chaillan et al., 2005; Restivo et al., 2006a; Restivo et al., 2006b). It is noteworthy that in humans, 5- $\mathrm{HT}_{4} \mathrm{R}$ levels in the hippocampus correlate with memory performance (Haahr et al., 2013), which carries an associated upregulation of receptor expression in the early stages of AD (Madsen et al., 2011b) and a marked loss of receptors in the hippocampus in the final stages of the pathology (Reynolds et al., 1995). Such observations support the importance of the regulation of $5-\mathrm{HT}_{4} \mathrm{R}$ levels, and probably of receptor activity, for hippocampal functions. The beneficial effects of RS 67333 on glial reactivity and amyloid plaques in the entorhinal cortex may contribute to preserving a functional connectivity between the entorhinal cortex and the hippocampus through the perforant pathway. Indeed, as previously demonstrated, hippocampal denervation of lateral olfactory tract projections at the level of the entorhinal cortex cause a rapid forgetting of olfactory memory, similar to an anterograde amnesia typically found in humans with hippocampal damages (Staubli et al., 1986). A recent study demonstrated that the injection of $A \beta_{42}$ into the entorhinal cortex induced synaptic impairments of this connecting pathway (Gholami Pourbadie et al., 2016). Our current observations in male mice confirm the decrease in microglia activation and amyloid burden that we previously showed in the brains of 5xFAD female mice after chronic treatment with a 5-HT 4 R agonist (Giannoni et al., 2013). In this former work, we demonstrated that a transient increase in SAPP $\alpha$ in mouse brains and cerebrospinal fluid after RS 67333 administration could account for the neuroprotective effects induced by $5-\mathrm{HT}_{4} \mathrm{R}$ activation. Here, we detected no differences in sAPP species recognized by the 6E10 antibody (Fig. 4). An elegant study recently showed that viral over-expression of sAPP $\alpha$ in the hippocampus of another mouse model of $\mathrm{AD}(\mathrm{APP} / \mathrm{PS} 1$ mice) reduced $\mathrm{A} \beta$ species and plaque load, which involved the recruitment of microglia in the vicinity of plaques (Fol et al., 2016). As the effects of sAPP $\alpha$ and 5- $\mathrm{HT}_{4} \mathrm{R}$ activation on microglia seem to be diametrically opposed, the reduction in microglia reactivity induced by RS 67333 probably 
involves 5-HT 4 -mediated signaling pathways different from those that promote sAPP $\alpha$ generation. cAMP, a second messenger produced upon 5- $\mathrm{HT}_{4} \mathrm{R}$ stimulation and known to have anti-inflammatory and neuroprotective properties, may be another key factor that mediates the effects of RS 67333 (Heckman et al., 2015; Kim et al., 2000; Silveira and Linden, 2006). Further work will be necessary to decipher the mechanisms involved in the 5- $\mathrm{HT}_{4} \mathrm{R}$-mediated neuroprotection. Our study also highlights that the decrease in amyloid plaques is independent of $A \beta$ formation, as demonstrated by the stable levels of $\beta C T F$ (Fig. 4). However, monomeric $A \beta$ levels decreased following protocol 2 (Fig. 4). These results suggested that the beneficial effects of the 4-month treatment could be partly due to a potentiation of $\mathrm{A} \beta$ degradation. As previously demonstrated, $5-\mathrm{HT}_{4} \mathrm{R}$ activation induces the production of MMP-9 (Hashimoto et al., 2012), a metalloproteinase that can degrade soluble and fibrillar forms of A $\beta$ (Py et al., 2014; Yan et al., 2006). Further investigations are needed to study the impact of RS 67333 on the content of MMP-9 or other $A \beta$-degrading enzymes.

In our 5xFAD mice, RS 67333 efficiently reduced gliosis and the levels of two key inflammatory mediators, IL- $1 \beta$ and MCP-1. Interestingly, the specific decrease in IL- $1 \beta$ and MCP-1 signaling pathways has been associated with better learning and memory abilities (Baranger et al., 2016b; Hartlage-Rubsamen et al., 2015; Kitazawa et al., 2011), suggesting that RS 67333 could modify AD pathogenesis by targeting these inflammatory pathways in glial cells.

Furthermore, an important aspect of the present study is that treatments were all performed on male mice, in contrast to our previous work performed on females (Giannoni et al., 2013). Differences in the effects linked to $5-\mathrm{HT}_{4} \mathrm{R}$ agonist treatments could also be attributed to the sex-specific modulation of APP processing and/or $\mathrm{A} \beta$ production, as already demonstrated in $5 \mathrm{xFAD}$ female mice (Oakley et al., 2006) or for the 3xTg mouse model of AD (Hirata-Fukae et al., 2008). To date, it has been shown that $5 \mathrm{xFAD}$ females develop $\mathrm{AD}$ pathology in a more aggressive way compared to males, but the underlying mechanisms remain to be elucidated. Discrepancies between the sexes might be due to hormonal changes and associated processes (e.g., metabolism variations). Revealing the mechanisms underlying the aggressiveness of the phenotype in female mice may help in understanding why AD incidence is higher in women than in men (Chene et al., 2015; Dufouil et al., 2014; Vina and Lloret, 2010). Variations in 5-HT 4 receptor expression could also account for sex differences. In humans, a 
study reported $13 \%$ fewer receptor binding sites in the limbic system of women compared to men (Madsen et al., 2011a). Moreover, in support of gender differences in $5-\mathrm{HT}_{4} \mathrm{R}$ actions, prucalopride, a partial 5-HT $\mathrm{H}_{4} \mathrm{R}$ agonist, has been approved in Canada (2011) for the treatment of chronic constipation, resistant to laxatives, in adult female patients only (Tack et al., 2013). All these parameters need to be considered when analyzing the results to extend our knowledge of $\mathrm{AD}$ development and treatment efficacy.

\section{Conclusions}

The present results suggest that early targeting of the serotonin pathway in $A D$, especially in the entorhinal cortex, may be a potential therapeutic target with beneficial effects on glial reactivity and APP metabolism. Recently, a new promising chemical molecule called donecopride, which presents two complementary activities, 5- $\mathrm{HT}_{4} \mathrm{R}$ agonist activity and acetylcholinesterase inhibitory activity, has been shown to enhance behavioral abilities in WT mice in the novel object recognition test (Lecoutey et al., 2014; Rochais et al., 2015). Taken together, these studies confirm the effectiveness of targeting 5-HT $\mathrm{R}_{4}$ directly or within a multiple target strategy to prevent $\mathrm{AD}$ pathogenesis in pre-clinical settings, and pave the way to exploring new strategies in $\mathrm{AD}$ therapeutics.

\section{Funding}

This work was supported by funding from the CNRS and Aix Marseille Université, and by grants from the French National Agency for Research to SR and FR (MAD5) and to MK (PREVENTAD) and to the DHUNE project supported by A*MIDEX. This work was carried out thanks to the support of the A*MIDEX project (ANR-11-IDEX-0001-02) funded by the "Investissements d'Avenir" French Government program, managed by the ANR. It was also supported by a grant from France Alzheimer to SR, and by LECMA grants to SR, and MK. Additional support was provided by CNRS, INSERM, University of Montpellier, and the French National Agency of Research (ADAMGUARD) grants to JB and SC and by France Alzheimer and LECMA grants to SC. KB was granted a research associate fellowship by the French "Fondation Plan Alzheimer" and post-doctoral support from the LABEX A*MIDEX "Management des Talents” from Aix Marseille Université. 


\section{Authors' contributions}

KB, PG, SDG, SG, FG, DS, MM, SC, and FR performed the experiments, collected, analyzed and interpreted data. MK, JB, EMG, and SR contributed to designing the work, interpreting data and a critical revision of the manuscript. SC and FR developed the concept of the experiments and supervised the project. $\mathrm{KB}, \mathrm{PG}, \mathrm{SDG}, \mathrm{SR}, \mathrm{SC}$ and $\mathrm{FR}$ wrote the manuscript. All the authors approved the manuscript.

\section{Acknowledgements}

The authors would like to thank Guy Escoffier for his excellent technical support in managing the behavioral equipment.

\section{References}

Ansanay, H., Sebben, M., Bockaert, J., Dumuis, A., 1992. Characterization of homologous 5hydroxytryptamine4 receptor desensitization in colliculi neurons. Mol Pharmacol 42, 808-816.

Bachstetter, A. D., Norris, C. M., Sompol, P., Wilcock, D. M., Goulding, D., Neltner, J. H., St Clair, D., Watterson, D. M., Van Eldik, L. J., 2012. Early stage drug treatment that normalizes proinflammatory cytokine production attenuates synaptic dysfunction in a mouse model that exhibits age-dependent progression of Alzheimer's disease-related pathology. J Neurosci 32, 10201-10210.

Baranger, K., Bonnet, A. E., Girard, S. D., Paumier, J. M., Garcia-Gonzalez, L., Elmanaa, W., Bernard, A., Charrat, E., Stephan, D., Bauer, C., Moschke, K., Lichtenthaler, S. F., Roman, F. S., Checler, F., Khrestchatisky, M., Rivera, S., 2016a. MT5-MMP Promotes Alzheimer's Pathogenesis in the Frontal Cortex of 5xFAD Mice and APP Trafficking in vitro. Front Mol Neurosci 9, 163.

Baranger, K., Marchalant, Y., Bonnet, A. E., Crouzin, N., Carrete, A., Paumier, J. M., Py, N. A., Bernard, A., Bauer, C., Charrat, E., Moschke, K., Seiki, M., Vignes, M., Lichtenthaler, S. F., Checler, F., Khrestchatisky, M., Rivera, S., 2016b. MT5-MMP is a new pro-amyloidogenic proteinase that promotes amyloid pathology and cognitive decline in a transgenic mouse model of Alzheimer's disease. Cell Mol Life Sci 73, 217-236.

Baranger, K., Rivera, S., Liechti, F. D., Grandgirard, D., Bigas, J., Seco, J., Tarrago, T., Leib, S. L., Khrestchatisky, M., 2014. Endogenous and synthetic MMP inhibitors in CNS physiopathology. Prog Brain Res 214, 313-351.

Ben Haim, L., Carrillo-de Sauvage, M. A., Ceyzeriat, K., Escartin, C., 2015. Elusive roles for reactive astrocytes in neurodegenerative diseases. Front Cell Neurosci 9, 278.

Bockaert, J., Claeysen, S., Compan, V., Dumuis, A., 2011. 5-HT(4) receptors, a place in the sun: act two. Curr Opin Pharmacol 11, 87-93.

Braak, H., Braak, E., 1991. Neuropathological stageing of Alzheimer-related changes. Acta Neuropathol 82, 239-259. 
Cachard-Chastel, M., Devers, S., Sicsic, S., Langlois, M., Lezoualc'h, F., Gardier, A. M., Belzung, C., 2008. Prucalopride and donepezil act synergistically to reverse scopolamine-induced memory deficit in C57Bl/6j mice. Behav Brain Res 187, 455-461.

Chaillan, F. A., Marchetti, E., Soumireu-Mourat, B., Roman, F. S., 2005. Selective impairment of subcategories of long-term memory in mice with hippocampal lesions accessed by the olfactory tubing maze. Behav Brain Res 158, 285-292.

Chene, G., Beiser, A., Au, R., Preis, S. R., Wolf, P. A., Dufouil, C., Seshadri, S., 2015. Gender and incidence of dementia in the Framingham Heart Study from mid-adult life. Alzheimers Dement 11,310320.

Cho, S., Hu, Y., 2007. Activation of 5-HT4 receptors inhibits secretion of beta-amyloid peptides and increases neuronal survival. Exp Neurol 203, 274-278.

Cochet, M., Donneger, R., Cassier, E., Gaven, F., Lichtenthaler, S. F., Marin, P., Bockaert, J., Dumuis, A., Claeysen, S., 2013. 5-HT4 receptors constitutively promote the non-amyloidogenic pathway of APP cleavage and interact with ADAM10. ACS Chem Neurosci 4, 130-140.

Consolo, S., Arnaboldi, S., Giorgi, S., Russi, G., Ladinsky, H., 1994. 5-HT4 receptor stimulation facilitates acetylcholine release in rat frontal cortex. Neuroreport 5, 1230-1232.

Crouzin, N., Baranger, K., Cavalier, M., Marchalant, Y., Cohen-Solal, C., Roman, F. S., Khrestchatisky, M., Rivera, S., Feron, F., Vignes, M., 2013. Area-specific alterations of synaptic plasticity in the 5XFAD mouse model of Alzheimer's disease: dissociation between somatosensory cortex and hippocampus. PLoS One 8, e74667.

De Strooper, B., 2010. Proteases and proteolysis in Alzheimer disease: a multifactorial view on the disease process. Physiol Rev 90, 465-494.

Du, A. T., Schuff, N., Amend, D., Laakso, M. P., Hsu, Y. Y., Jagust, W. J., Yaffe, K., Kramer, J. H., Reed, B., Norman, D., Chui, H. C., Weiner, M. W., 2001. Magnetic resonance imaging of the entorhinal cortex and hippocampus in mild cognitive impairment and Alzheimer's disease. J Neurol Neurosurg Psychiatry 71, 441-447.

Dufouil, C., Seshadri, S., Chene, G., 2014. Cardiovascular risk profile in women and dementia. J Alzheimers Dis 42 Suppl 4, S353-363.

Fol, R., Braudeau, J., Ludewig, S., Abel, T., Weyer, S. W., Roederer, J. P., Brod, F., Audrain, M., Bemelmans, A. P., Buchholz, C. J., Korte, M., Cartier, N., Muller, U. C., 2016. Viral gene transfer of APPsalpha rescues synaptic failure in an Alzheimer's disease mouse model. Acta Neuropathol 131, 247266.

Fontana, D. J., Daniels, S. E., Wong, E. H., Clark, R. D., Eglen, R. M., 1997. The effects of novel, selective 5-hydroxytryptamine (5-HT)4 receptor ligands in rat spatial navigation. Neuropharmacology 36, 689-696.

Freret, T., Bouet, V., Quiedeville, A., Nee, G., Dallemagne, P., Rochais, C., Boulouard, M., 2012. Synergistic effect of acetylcholinesterase inhibition (donepezil) and 5-HT(4) receptor activation (RS67333) on object recognition in mice. Behav Brain Res 230, 304-308.

Gholami Pourbadie, H., Naderi, N., Janahmadi, M., Mehranfard, N., Motamedi, F., 2016. Calcium channel blockade attenuates abnormal synaptic transmission in the dentate gyrus elicited by entorhinal amyloidopathy. Synapse 70, 408-417.

Giannakopoulos, P., Gold, G., Duc, M., Michel, J. P., Hof, P. R., Bouras, C., 2000. Neural substrates of spatial and temporal disorientation in Alzheimer's disease. Acta Neuropathol 100, 189-195.

Giannoni, P., Arango-Lievano, M., Neves, I. D., Rousset, M. C., Baranger, K., Rivera, S., Jeanneteau, F., Claeysen, S., Marchi, N., 2016. Cerebrovascular pathology during the progression of experimental Alzheimer's disease. Neurobiol Dis 88, 107-117. 
Giannoni, P., Gaven, F., de Bundel, D., Baranger, K., Marchetti-Gauthier, E., Roman, F. S., Valjent, E., Marin, P., Bockaert, J., Rivera, S., Claeysen, S., 2013. Early administration of RS 67333, a specific 5HT4 receptor agonist, prevents amyloidogenesis and behavioral deficits in the 5XFAD mouse model of Alzheimer's disease. Front Aging Neurosci 5, 96.

Girard, S. D., Escoffier, G., Khrestchatisky, M., Roman, F. S., 2016. The FVB/N mice: A well suited strain to study learning and memory processes using olfactory cues. Behav Brain Res 296, 254-259.

Girard, S. D., Jacquet, M., Baranger, K., Migliorati, M., Escoffier, G., Bernard, A., Khrestchatisky, M., Feron, F., Rivera, S., Roman, F. S., Marchetti, E., 2014. Onset of hippocampus-dependent memory impairments in 5XFAD transgenic mouse model of Alzheimer's disease. Hippocampus 24, 762-772.

Haahr, M. E., Fisher, P., Holst, K., Madsen, K., Jensen, C. G., Marner, L., Lehel, S., Baare, W., Knudsen, G., Hasselbalch, S., 2013. The 5-HT4 receptor levels in hippocampus correlates inversely with memory test performance in humans. Hum Brain Mapp 34, 3066-3074.

Hartlage-Rubsamen, M., Waniek, A., Meissner, J., Morawski, M., Schilling, S., Jager, C., Kleinschmidt, M., Cynis, H., Kehlen, A., Arendt, T., Demuth, H. U., Rossner, S., 2015. Isoglutaminyl cyclase contributes to CCL2-driven neuroinflammation in Alzheimer's disease. Acta Neuropathol 129, 565-583.

Hashimoto, G., Sakurai, M., Teich, A. F., Saeed, F., Aziz, F., Arancio, O., 2012. 5-HT(4) receptor stimulation leads to soluble AbetaPPalpha production through MMP-9 upregulation. J Alzheimers Dis $32,437-445$

Heckman, P. R., Wouters, C., Prickaerts, J., 2015. Phosphodiesterase inhibitors as a target for cognition enhancement in aging and Alzheimer's disease: a translational overview. Curr Pharm Des 21, 317-331.

Heneka, M. T., Carson, M. J., El Khoury, J., Landreth, G. E., Brosseron, F., Feinstein, D. L., Jacobs, A. H., Wyss-Coray, T., Vitorica, J., Ransohoff, R. M., Herrup, K., Frautschy, S. A., Finsen, B., Brown, G. C., Verkhratsky, A., Yamanaka, K., Koistinaho, J., Latz, E., Halle, A., Petzold, G. C., Town, T., Morgan, D., Shinohara, M. L., Perry, V. H., Holmes, C., Bazan, N. G., Brooks, D. J., Hunot, S., Joseph, B., Deigendesch, N., Garaschuk, O., Boddeke, E., Dinarello, C. A., Breitner, J. C., Cole, G. M., Golenbock, D. T., Kummer, M. P., 2015. Neuroinflammation in Alzheimer's disease. Lancet Neurol 14, 388-405.

Herholz, K., Weisenbach, S., Kalbe, E., 2008. Deficits of the cholinergic system in early AD. Neuropsychologia 46, 1642-1647.

Hirata-Fukae, C., Li, H. F., Hoe, H. S., Gray, A. J., Minami, S. S., Hamada, K., Niikura, T., Hua, F., Tsukagoshi-Nagai, H., Horikoshi-Sakuraba, Y., Mughal, M., Rebeck, G. W., LaFerla, F. M., Mattson, M. P., Iwata, N., Saido, T. C., Klein, W. L., Duff, K. E., Aisen, P. S., Matsuoka, Y., 2008. Females exhibit more extensive amyloid, but not tau, pathology in an Alzheimer transgenic model. Brain Res 1216, 92-103.

Hodges, J. R., Patterson, K., 1995. Is semantic memory consistently impaired early in the course of Alzheimer's disease? Neuroanatomical and diagnostic implications. Neuropsychologia 33, 441-459.

Johnson, D. E., Drummond, E., Grimwood, S., Sawant-Basak, A., Miller, E., Tseng, E., McDowell, L. L., Vanase-Frawley, M. A., Fisher, K. E., Rubitski, D. M., Stutzman-Engwall, K. J., Nelson, R. T., Horner, W. E., Gorczyca, R. R., Hajos, M., Siok, C. J., 2012. The 5-hydroxytryptamine4 receptor agonists prucalopride and PRX-03140 increase acetylcholine and histamine levels in the rat prefrontal cortex and the power of stimulated hippocampal theta oscillations. J Pharmacol Exp Ther 341, 681-691.

Jourquin, J., Tremblay, E., Bernard, A., Charton, G., Chaillan, F. A., Marchetti, E., Roman, F. S., Soloway, P. D., Dive, V., Yiotakis, A., Khrestchatisky, M., Rivera, S., 2005. Tissue inhibitor of metalloproteinases-1 (TIMP-1) modulates neuronal death, axonal plasticity, and learning and memory. Eur J Neurosci 22, 2569-2578.

Khan, U. A., Liu, L., Provenzano, F. A., Berman, D. E., Profaci, C. P., Sloan, R., Mayeux, R., Duff, K. E., Small, S. A., 2014. Molecular drivers and cortical spread of lateral entorhinal cortex dysfunction in preclinical Alzheimer's disease. Nat Neurosci 17, 304-311. 
Kim, W. K., Kan, Y., Ganea, D., Hart, R. P., Gozes, I., Jonakait, G. M., 2000. Vasoactive intestinal peptide and pituitary adenylyl cyclase-activating polypeptide inhibit tumor necrosis factor-alpha production in injured spinal cord and in activated microglia via a cAMP-dependent pathway. J Neurosci 20, 3622-3630.

Kitazawa, M., Cheng, D., Tsukamoto, M. R., Koike, M. A., Wes, P. D., Vasilevko, V., Cribbs, D. H., LaFerla, F. M., 2011. Blocking IL-1 signaling rescues cognition, attenuates tau pathology, and restores neuronal beta-catenin pathway function in an Alzheimer's disease model. J Immunol 187, 6539-6549.

Kuhn, P. H., Wang, H., Dislich, B., Colombo, A., Zeitschel, U., Ellwart, J. W., Kremmer, E., Rossner, S., Lichtenthaler, S. F., 2010. ADAM10 is the physiologically relevant, constitutive alpha-secretase of the amyloid precursor protein in primary neurons. EMBO J 29, 3020-3032.

Lecoutey, C., Hedou, D., Freret, T., Giannoni, P., Gaven, F., Since, M., Bouet, V., Ballandonne, C., Corvaisier, S., Malzert Freon, A., Mignani, S., Cresteil, T., Boulouard, M., Claeysen, S., Rochais, C., Dallemagne, P., 2014. Design of donecopride, a dual serotonin subtype 4 receptor agonist/acetylcholinesterase inhibitor with potential interest for Alzheimer's disease treatment. Proc Natl Acad Sci U S A 111, E3825-3830.

Letty, S., Child, R., Dumuis, A., Pantaloni, A., Bockaert, J., Rondouin, G., 1997. 5-HT4 receptors improve social olfactory memory in the rat. Neuropharmacology 36, 681-687.

Li, Y., Tan, M. S., Jiang, T., Tan, L., 2014. Microglia in Alzheimer's disease. Biomed Res Int 2014, 437483.

Lo, A. C., De Maeyer, J. H., Vermaercke, B., Callaerts-Vegh, Z., Schuurkes, J. A., D'Hooge, R., 2014. SSP-002392, a new 5-HT4 receptor agonist, dose-dependently reverses scopolamine-induced learning and memory impairments in C57Bl/6 mice. Neuropharmacology 85, 178-189.

Madsen, K., Haahr, M. T., Marner, L., Keller, S. H., Baare, W. F., Svarer, C., Hasselbalch, S. G., Knudsen, G. M., 2011a. Age and sex effects on 5-HT(4) receptors in the human brain: a [(11)C]SB207145 PET study. J Cereb Blood Flow Metab 31, 1475-1481.

Madsen, K., Neumann, W. J., Holst, K., Marner, L., Haahr, M. T., Lehel, S., Knudsen, G. M., Hasselbalch, S. G., 2011b. Cerebral serotonin 4 receptors and amyloid-beta in early Alzheimer's disease. J Alzheimers Dis 26, 457-466.

Maillet, M., Robert, S. J., Cacquevel, M., Gastineau, M., Vivien, D., Bertoglio, J., Zugaza, J. L., Fischmeister, R., Lezoualc'h, F., 2003. Crosstalk between Rap1 and Rac regulates secretion of sAPPalpha. Nat Cell Biol 5, 633-639.

Manuel-Apolinar, L., Rocha, L., Pascoe, D., Castillo, E., Castillo, C., Meneses, A., 2005. Modifications of 5-HT4 receptor expression in rat brain during memory consolidation. Brain Res 1042, 73-81.

Marchetti-Gauthier, E., Roman, F. S., Dumuis, A., Bockaert, J., Soumireu-Mourat, B., 1997. BIMU1 increases associative memory in rats by activating 5-HT4 receptors. Neuropharmacology 36, 697-706.

Marchetti, E., Chaillan, F. A., Dumuis, A., Bockaert, J., Soumireu-Mourat, B., Roman, F. S., 2004. Modulation of memory processes and cellular excitability in the dentate gyrus of freely moving rats by a 5-HT4 receptors partial agonist, and an antagonist. Neuropharmacology 47, 1021-1035.

Marchetti, E., Dumuis, A., Bockaert, J., Soumireu-Mourat, B., Roman, F. S., 2000. Differential modulation of the 5-HT(4) receptor agonists and antagonist on rat learning and memory. Neuropharmacology 39, 2017-2027.

Marchetti, E., Jacquet, M., Escoffier, G., Miglioratti, M., Dumuis, A., Bockaert, J., Roman, F. S., 2011. Enhancement of reference memory in aged rats by specific activation of 5-HT(4) receptors using an olfactory associative discrimination task. Brain Res 1405, 49-56.

Nhan, H. S., Chiang, K., Koo, E. H., 2015. The multifaceted nature of amyloid precursor protein and its proteolytic fragments: friends and foes. Acta Neuropathol 129, 1-19. 
Oakley, H., Cole, S. L., Logan, S., Maus, E., Shao, P., Craft, J., Guillozet-Bongaarts, A., Ohno, M., Disterhoft, J., Van Eldik, L., Berry, R., Vassar, R., 2006. Intraneuronal beta-amyloid aggregates, neurodegeneration, and neuron loss in transgenic mice with five familial Alzheimer's disease mutations: potential factors in amyloid plaque formation. J Neurosci 26, 10129-10140.

Pike, K. E., Savage, G., Villemagne, V. L., Ng, S., Moss, S. A., Maruff, P., Mathis, C. A., Klunk, W. E., Masters, C. L., Rowe, C. C., 2007. Beta-amyloid imaging and memory in non-demented individuals: evidence for preclinical Alzheimer's disease. Brain 130, 2837-2844.

Py, N. A., Bonnet, A. E., Bernard, A., Marchalant, Y., Charrat, E., Checler, F., Khrestchatisky, M., Baranger, K., Rivera, S., 2014. Differential spatio-temporal regulation of MMPs in the 5xFAD mouse model of Alzheimer's disease: evidence for a pro-amyloidogenic role of MT1-MMP. Front Aging Neurosci 6, 247.

Restivo, L., Chaillan, F. A., Ammassari-Teule, M., Roman, F. S., Marchetti, E., 2006a. Strain differences in rewarded discrimination learning using the olfactory tubing maze. Behav Genet 36, 923934.

Restivo, L., Roman, F., Dumuis, A., Bockaert, J., Marchetti, E., Ammassari-Teule, M., 2008. The promnesic effect of G-protein-coupled 5-HT4 receptors activation is mediated by a potentiation of learning-induced spine growth in the mouse hippocampus. Neuropsychopharmacology 33, 2427-2434.

Restivo, L., Roman, F. S., Ammassari-Teule, M., Marchetti, E., 2006b. Simultaneous olfactory discrimination elicits a strain-specific increase in dendritic spines in the hippocampus of inbred mice. Hippocampus 16, 472-479.

Reynolds, G. P., Mason, S. L., Meldrum, A., De Keczer, S., Parnes, H., Eglen, R. M., Wong, E. H., 1995. 5-Hydroxytryptamine (5-HT)4 receptors in post mortem human brain tissue: distribution, pharmacology and effects of neurodegenerative diseases. Br J Pharmacol 114, 993-998.

Rochais, C., Lecoutey, C., Gaven, F., Giannoni, P., Hamidouche, K., Hedou, D., Dubost, E., Genest, D., Yahiaoui, S., Freret, T., Bouet, V., Dauphin, F., Sopkova de Oliveira Santos, J., Ballandonne, C., Corvaisier, S., Malzert-Freon, A., Legay, R., Boulouard, M., Claeysen, S., Dallemagne, P., 2015. Novel multitarget-directed ligands (MTDLs) with acetylcholinesterase (AChE) inhibitory and serotonergic subtype 4 receptor (5-HT4R) agonist activities as potential agents against Alzheimer's disease: the design of donecopride. J Med Chem 58, 3172-3187.

Roddick, K. M., Roberts, A. D., Schellinck, H. M., Brown, R. E., 2016. Sex and Genotype Differences in Odor Detection in the 3xTg-AD and 5XFAD Mouse Models of Alzheimer's Disease at 6 Months of Age. Chem Senses 41, 433-440.

Roman, F. S., Marchetti, E., Bouquerel, A., Soumireu-Mourat, B., 2002. The olfactory tubing maze: a new apparatus for studying learning and memory processes in mice. J Neurosci Methods 117, 173-181.

Rowe, C. C., Villemagne, V. L., 2013. Brain amyloid imaging. J Nucl Med Technol 41, 11-18.

Selkoe, D. J., 2008. Soluble oligomers of the amyloid beta-protein impair synaptic plasticity and behavior. Behav Brain Res 192, 106-113.

Selkoe, D. J., Hardy, J., 2016. The amyloid hypothesis of Alzheimer's disease at 25 years. EMBO Mol Med 8, 595-608.

Silveira, M. S., Linden, R., 2006. Neuroprotection by cAMP: Another brick in the wall. Adv Exp Med Biol 557, 164-176.

Squire, L. R., Wixted, J. T., 2011. The cognitive neuroscience of human memory since H.M. Annu Rev Neurosci 34, 259-288.

Staubli, U., Fraser, D., Kessler, M., Lynch, G., 1986. Studies on retrograde and anterograde amnesia of olfactory memory after denervation of the hippocampus by entorhinal cortex lesions. Behav Neural Biol $46,432-444$ 
Tack, J., Quigley, E., Camilleri, M., Vandeplassche, L., Kerstens, R., 2013. Efficacy and safety of oral prucalopride in women with chronic constipation in whom laxatives have failed: an integrated analysis. United European Gastroenterol J 1, 48-59.

Terry, A. V., Jr., Buccafusco, J. J., Jackson, W. J., Prendergast, M. A., Fontana, D. J., Wong, E. H., Bonhaus, D. W., Weller, P., Eglen, R. M., 1998. Enhanced delayed matching performance in younger and older macaques administered the 5-HT4 receptor agonist, RS 17017. Psychopharmacology (Berl) 135, 407-415.

Tesseur, I., Pimenova, A. A., Lo, A. C., Ciesielska, M., Lichtenthaler, S. F., De Maeyer, J. H., Schuurkes, J. A., D'Hooge, R., De Strooper, B., 2013. Chronic 5-HT4 receptor activation decreases Abeta production and deposition in hAPP/PS1 mice. Neurobiol Aging 34, 1779-1789.

Thathiah, A., De Strooper, B., 2011. The role of G protein-coupled receptors in the pathology of Alzheimer's disease. Nat Rev Neurosci 12, 73-87.

Varnas, K., Halldin, C., Pike, V. W., Hall, H., 2003. Distribution of 5-HT4 receptors in the postmortem human brain--an autoradiographic study using [125I]SB 207710. Eur Neuropsychopharmacol 13, 228234.

Velayudhan, L., Proitsi, P., Westman, E., Muehlboeck, J. S., Mecocci, P., Vellas, B., Tsolaki, M., Kloszewska, I., Soininen, H., Spenger, C., Hodges, A., Powell, J., Lovestone, S., Simmons, A., dNeuroMed, C., 2013. Entorhinal cortex thickness predicts cognitive decline in Alzheimer's disease. J Alzheimers Dis 33, 755-766.

Vina, J., Lloret, A., 2010. Why women have more Alzheimer's disease than men: gender and mitochondrial toxicity of amyloid-beta peptide. J Alzheimers Dis 20 Suppl 2, S527-533.

Walsh, D. M., Klyubin, I., Fadeeva, J. V., Cullen, W. K., Anwyl, R., Wolfe, M. S., Rowan, M. J., Selkoe, D. J., 2002. Naturally secreted oligomers of amyloid beta protein potently inhibit hippocampal longterm potentiation in vivo. Nature 416, 535-539.

Willem, M., Tahirovic, S., Busche, M. A., Ovsepian, S. V., Chafai, M., Kootar, S., Hornburg, D., Evans, L. D., Moore, S., Daria, A., Hampel, H., Muller, V., Giudici, C., Nuscher, B., Wenninger-Weinzierl, A., Kremmer, E., Heneka, M. T., Thal, D. R., Giedraitis, V., Lannfelt, L., Muller, U., Livesey, F. J., Meissner, F., Herms, J., Konnerth, A., Marie, H., Haass, C., 2015. eta-Secretase processing of APP inhibits neuronal activity in the hippocampus. Nature 526, 443-447.

Wyss-Coray, T., Loike, J. D., Brionne, T. C., Lu, E., Anankov, R., Yan, F., Silverstein, S. C., Husemann, J., 2003. Adult mouse astrocytes degrade amyloid-beta in vitro and in situ. Nat Med 9, 453-457.

Wyss-Coray, T., Rogers, J., 2012. Inflammation in Alzheimer disease-a brief review of the basic science and clinical literature. Cold Spring Harb Perspect Med 2, a006346.

Yan, P., Hu, X., Song, H., Yin, K., Bateman, R. J., Cirrito, J. R., Xiao, Q., Hsu, F. F., Turk, J. W., Xu, J., Hsu, C. Y., Holtzman, D. M., Lee, J. M., 2006. Matrix metalloproteinase-9 degrades amyloid-beta fibrils in vitro and compact plaques in situ. J Biol Chem 281, 24566-24574.

Zhang, Z., Song, M., Liu, X., Su Kang, S., Duong, D. M., Seyfried, N. T., Cao, X., Cheng, L., Sun, Y. E., Ping Yu, S., Jia, J., Levey, A. I., Ye, K., 2015. Delta-secretase cleaves amyloid precursor protein and regulates the pathogenesis in Alzheimer's disease. Nat Commun 6, 8762.

\section{Figure legends}

\section{Figure 1. The olfactory tubing maze (OTM).}

A. Photograph showing a top view of the OTM apparatus set on a table. The OTM is composed of four identical "Testing Chambers" joined to each other by plastic tubes organized in a circular structure (TC 
1 to 4). Each TC is connected to the two lateral arms which simultaneously and randomly deliver two synthetic odors arbitrarily associated either with a drop of water (the reward) or with an unpleasant buzzing sound, depending on the arm chosen by mice. The orange and green arrows (odor 1 and odor 2) indicate the direction of the diffusing odor released by the extremities of the lateral arms thanks to the inverted exhaust fans placed above each testing chambers. The "entrance" indicates the place where the mouse is introduced and the black arrows the mouse moving direction. In the TC1, the violet arrows illustrate a "backtrack" in which, after a response, a mouse make a U-turn towards the previous TC instead of moving ahead towards the next TC in a clockwise direction. B. Photograph of a lateral tube extremity showing air and water ports allowing odor and reward delivery. C. Photograph of a testing chamber showing the inverted fan and the automated doors (entrance and exit), which successively and automatically open and close and impose to the mice a clockwise moving direction into the maze.

Figure 2. Chronic administration of RS 67333 reduces the amyloid plaque load in the entorhinal cortex of 5xFAD mice.

A. Schematic model of the progression of the AD-like pathology in 5xFAD mice. $A \beta$ accumulation and amyloid plaque formation start at 2 months of age, concomitant with increased glial reactivity. The first behavioral deficits appear between 4 and 6 months of age, prior to overt neuropathological alterations and severe cognitive decline. The time-course of the two different treatment protocols (protocol 1 and 2) with the 5-HT 4 receptor agonist RS $67333(1 \mathrm{mg} / \mathrm{kg}$, i.p., twice a week) is shown below the diagram of disease progression. At the end of the treatment (green arrows), the behavioral experiments in the Olfactory Tubing Maze (OTM) were performed. Mice were then sacrificed, and amyloid plaques and glial reactivity evaluated in brain slices. B. Representative epifluorescence microphotographs of thioflavin $\mathrm{T}$ staining of amyloid plaques in the frontal cortex $(\mathrm{a}, \mathrm{d})$, hippocampus $(\mathrm{b}, \mathrm{e})$ and entorhinal cortex (c, f) from vehicle-treated 5xFAD (Vehicle) or RS 67333-treated mice (RS 67333) according to protocol 2. Quantification of amyloid plaque load (number of plaques $/ \mathrm{mm}^{2}$ ) in the frontal cortex (C), hippocampus (D) and entorhinal cortex (E) following RS 67333 treatment using protocol 1 and protocol 2. Values are the mean \pm SEM of 7-8 mice per group. ${ }^{*} p<0.05 ; * * * p<0.001$, ANOVA followed by posthoc Fisher's LSD test. Scale bars: $200 \mu \mathrm{m}$. I-VI, cortical layers I to VI; Cx: cortex; DG: hippocampal dentate gyrus; PRh: Perirhinal cortex; DIEnt: dorsal intermediate entorhinal field; CA1-CA3: Cornu Ammonis 1 to 3 of the hippocampus; Th: thalamus; cc: corpus callosum. 
Figure 3. Chronic administration of RS 67333 reduces glial reactivity and the content of inflammatory mediators in the entorhinal cortex of 5xFAD mice.

A. Representative epifluorescence microphotographs showing staining of amyloid plaques (6E10, green) and astrocytes (GFAP, red) in the entorhinal cortex from 5xFAD mice treated with RS 67333 (protocol 2) or vehicle alone. B. Quantification of GFAP staining (\% of analyzed area) in the entorhinal cortex following RS 67333 treatment using protocols 1 and 2. C. Representative epifluorescence microphotographs showing staining of amyloid plaques (6E10, green) and microglial reactivity (Iba1, red) in the entorhinal cortex from 5xFAD mice treated with RS 67333 (protocol 2) or vehicle alone. D. Quantification of Ibal staining (\% of analyzed area) in the entorhinal cortex following RS 67333 treatment using protocols 1 and 2 . Values are the mean \pm SEM of 7-8 mice per group. Western blot analysis $(\mathbf{E})$ and quantification $(\mathbf{F})$ of GFAP in the soluble fraction. Actin-normalized values are the mean \pm SEM of 5-6 mice per genotype. ${ }^{*} p<0.05$, ANOVA followed by post-hoc Fisher's LSD test. A.U., arbitrary units. ELISA assay showing quantification of IL-1 1 (G) and MCP-1 (H) levels $(\mathrm{pg} / \mathrm{mL}$ of protein) in the Triton soluble fraction of the entorhinal cortex from 5xFAD mice. Values are the mean \pm SEM of 7-8 mice per genotype. ${ }^{*} p<0.05 ;{ }^{* *} p<0.01 ; * * * p<0.001$, ANOVA followed by post-hoc Bonferroni's or Fisher's LSD test.

Figure 4. Chronic administration of RS 67333 reduced GFAP levels without affecting APP/Aß metabolism in the entorhinal cortex of 5XFAD mice.

A. Western blot analysis (upper panel) and quantification (lower panel) of APP using specific antibodies against the APP N-terminal domain (22C11 and the N-terminal part of the human A $\beta$ sequence (6E10). Actin-normalized values are the mean \pm SEM of 5-6 mice per genotype. ${ }^{*} p<0.05 ; * * p<0.01$, ANOVA followed by post-hoc Fisher's LSD test. A.U., arbitrary units. B. Western blot analysis (upper panel) and quantification (lower panel) of C-terminal fragments (CTFs) of APP (APP-CTF antibody) and A $\beta$ levels (6E10 antibody) in the insoluble fraction. GAPDH-normalized values are the mean \pm SEM of 56 mice per genotype. ANOVA followed by post-hoc Fisher's LSD test. A.U., arbitrary units. $\beta C$ TF: $\beta$ secretase-derived C-terminal fragment of APP, $\alpha \mathrm{CTF}: \alpha$-secretase-derived C-terminal fragment of APP. 
Figure 5. Learning performance in the OTM after chronic administration of RS 67333 following protocol 1.

Results obtained during seven training sessions of 12 trials per day with 4-month-old male mice. A-D. Mean percentage of correct responses. The dashed line denotes the chance level. Mean cumulative time in seconds $(\mathbf{E}-\mathbf{H})$ and mean number of backtracks (I-L) during the 12 daily trials. The data are presented as the mean $+/$ - SEM, 8 mice per group.

Figure 6. Learning performance in the OTM after chronic administration of RS 67333 following protocol 2.

Results obtained during seven training sessions of 12 trials per day with 6-month-old mice. A-D. Mean percentage of correct responses. The dashed line denotes the chance level. Mean cumulative time in seconds $(\mathbf{E}-\mathbf{H})$ and mean number of backtracks (I-L) during the 12 daily trials. The data are presented as the mean $+/$ - SEM, 7 mice per group. 


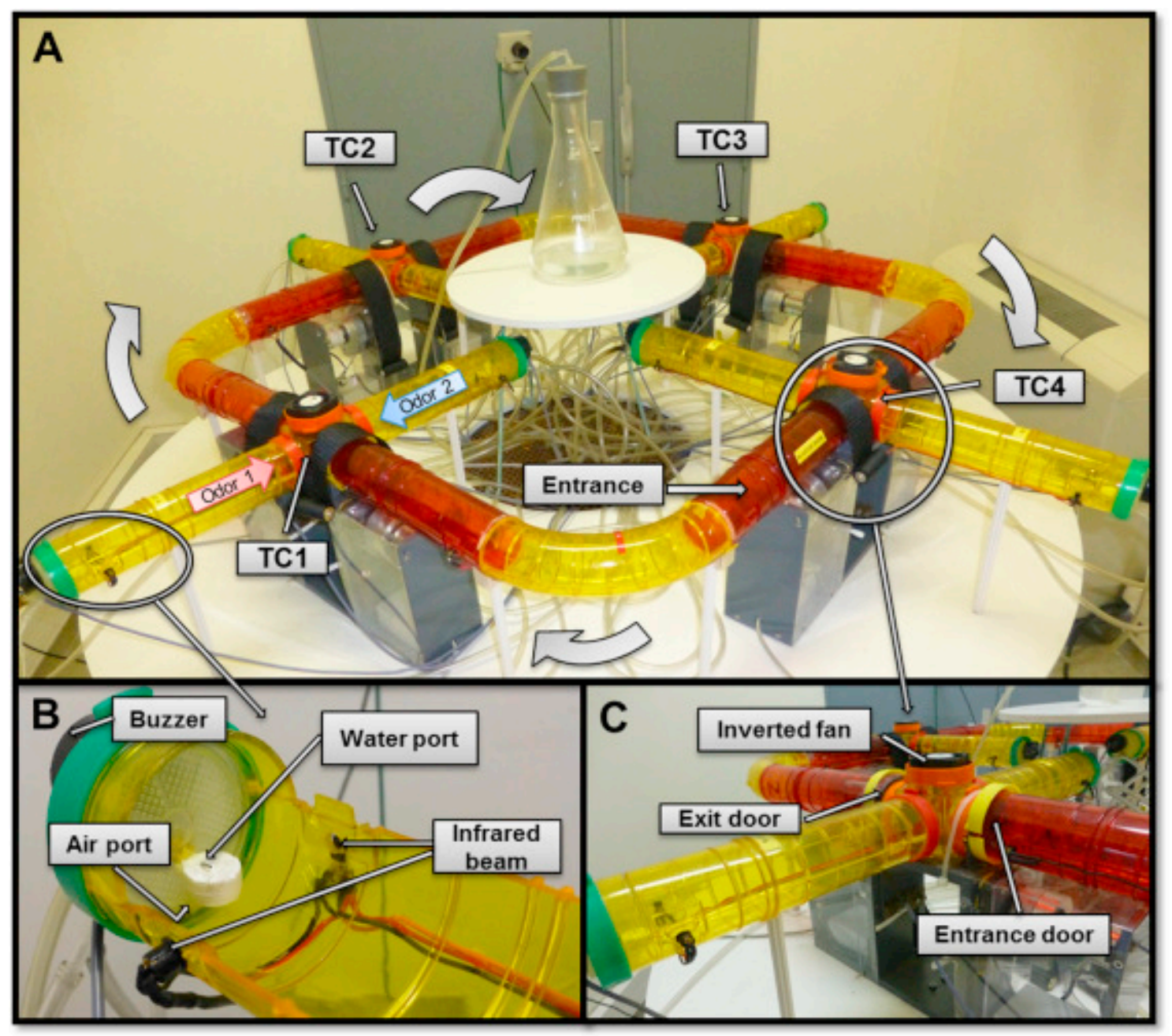

Figure 1 
A

5xFAD mice
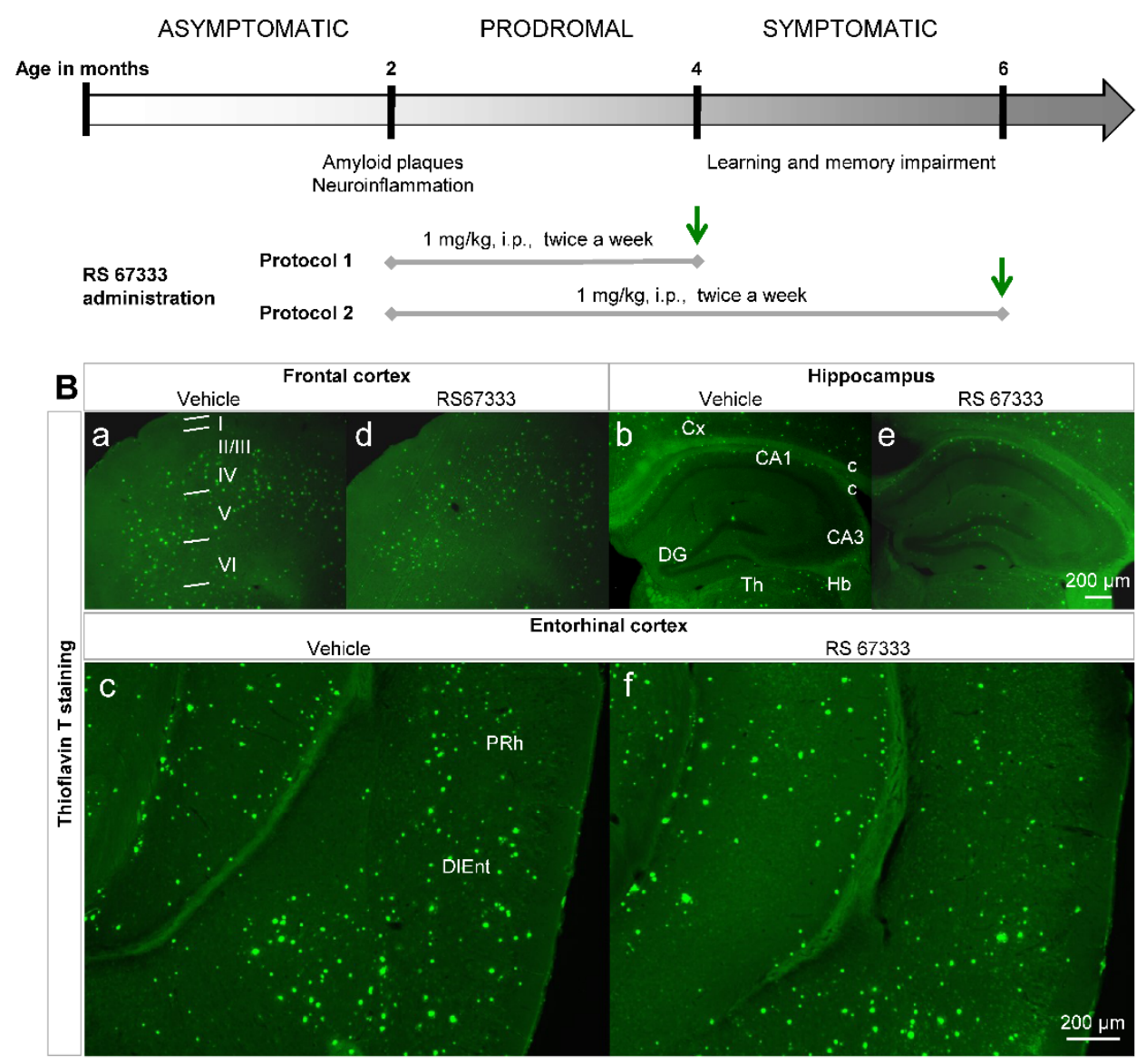
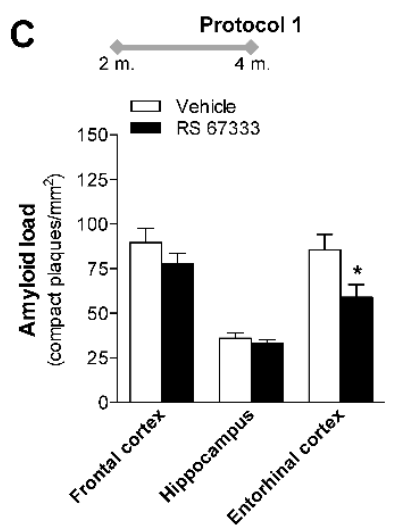
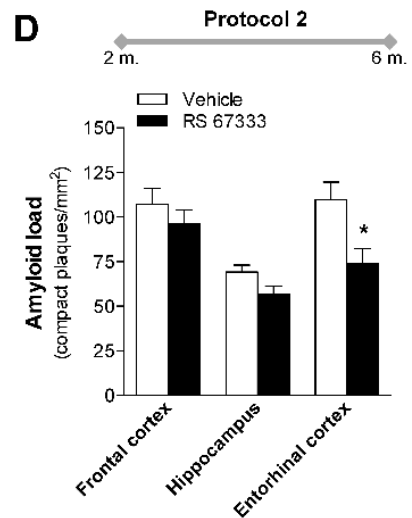

Figure 2 

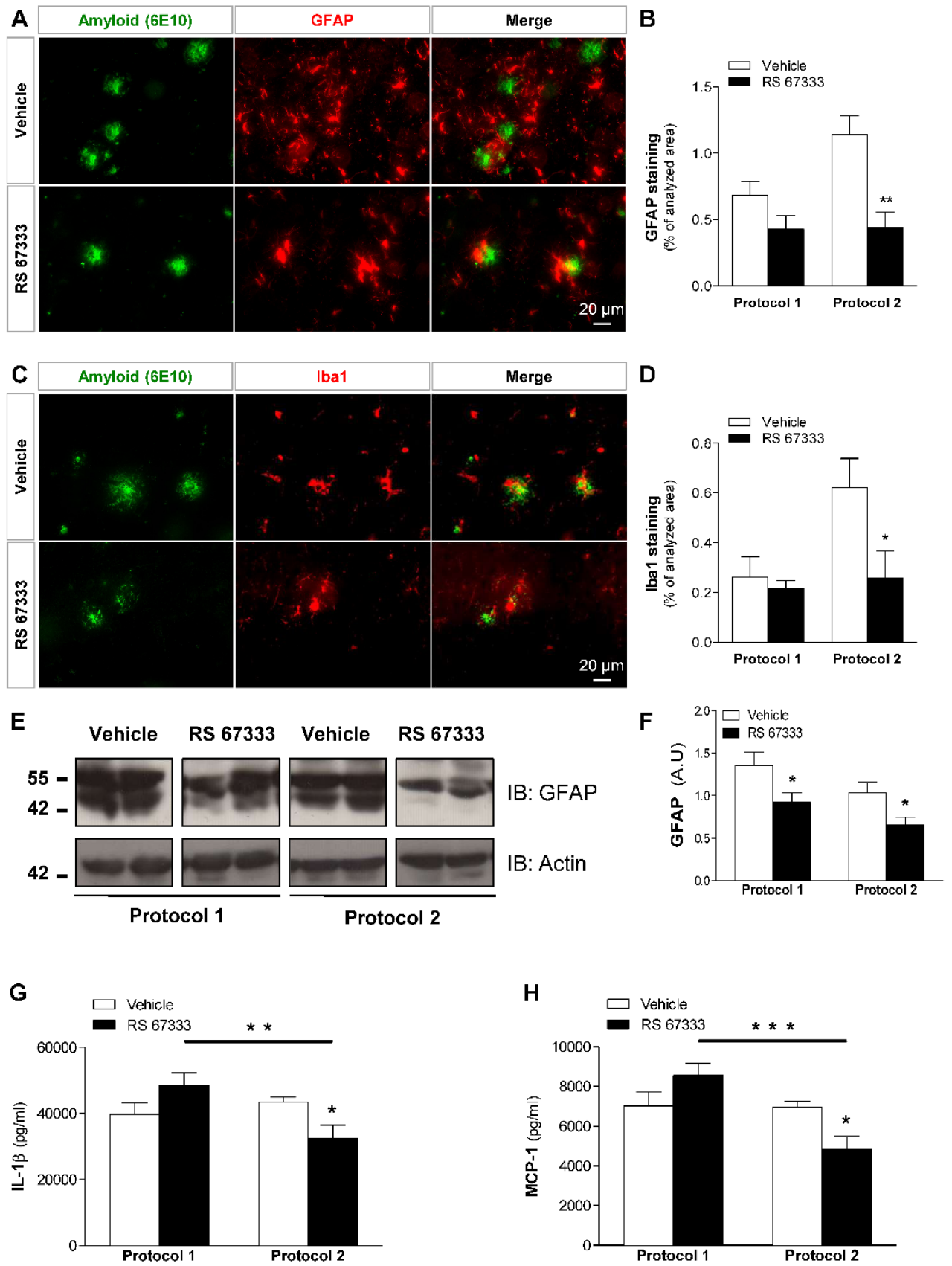

Figure 3 
A.
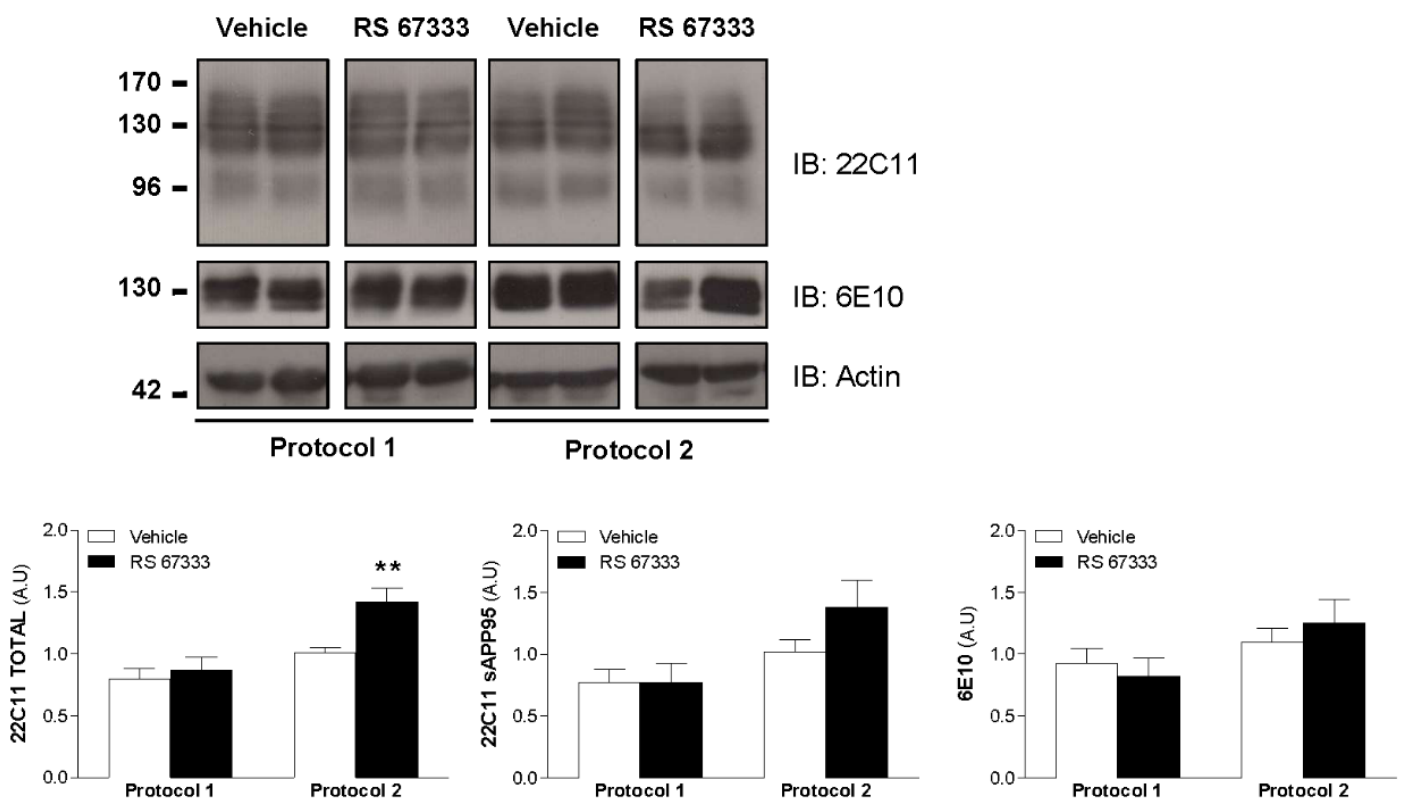

B.
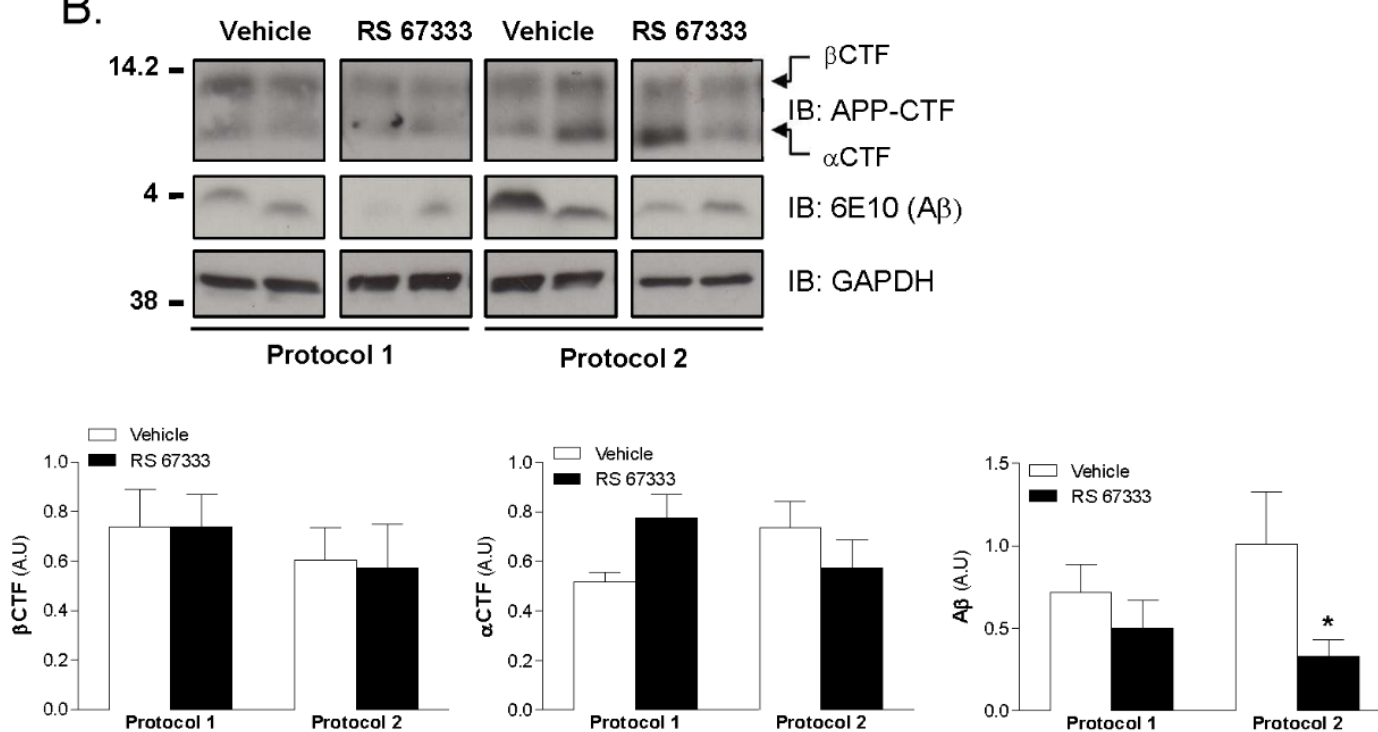

Figure 4 


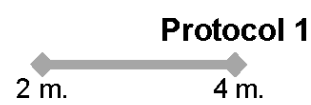

A E

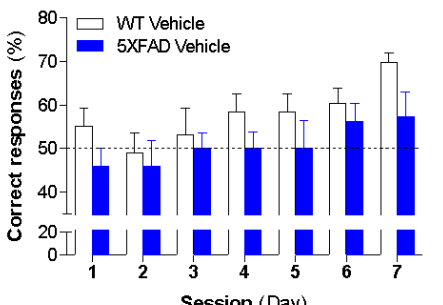

B
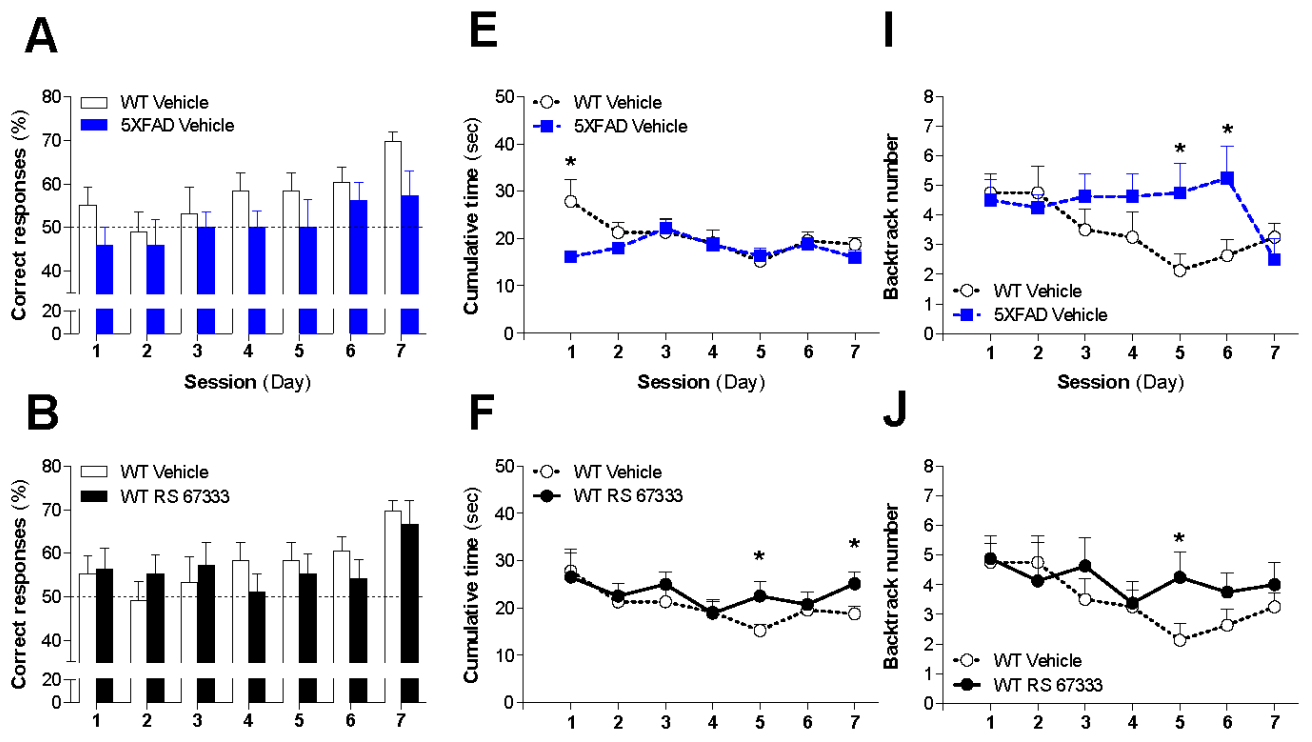

C
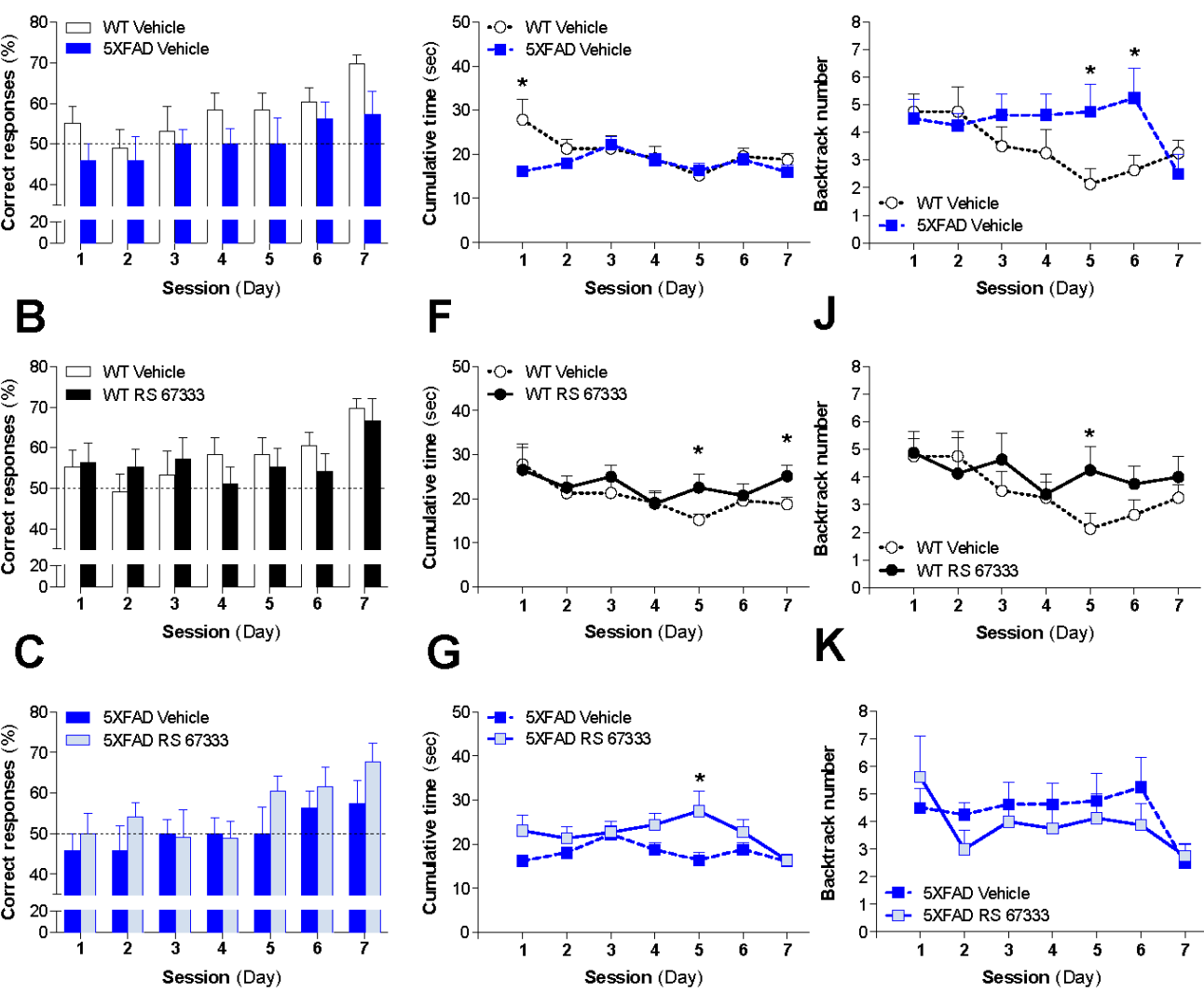

G

$\mathrm{K}$
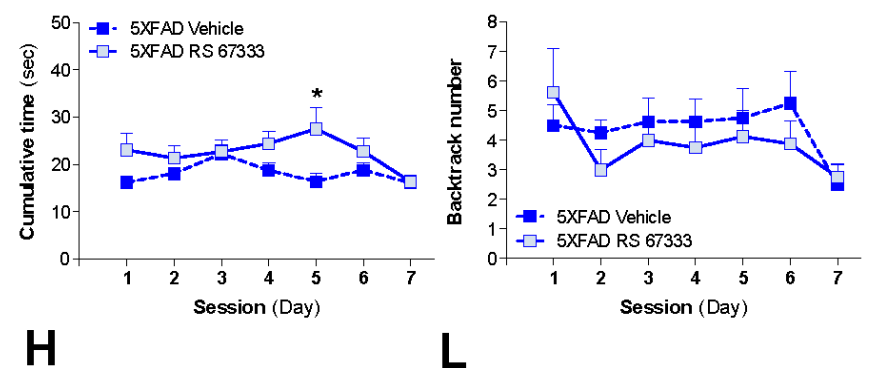

D

$\mathrm{H}$
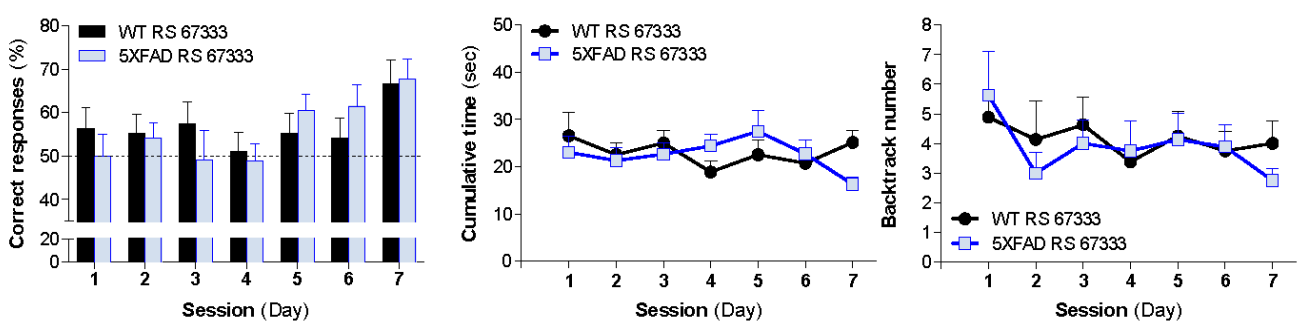

Figure 5 
Protocol 2

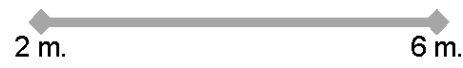

A

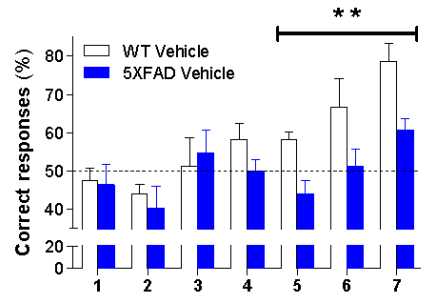

B

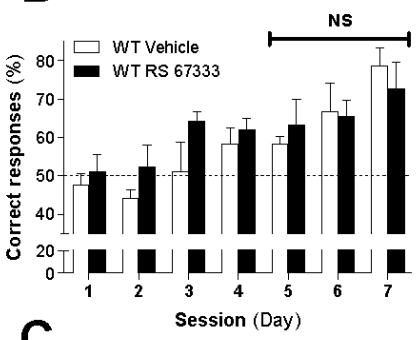

C

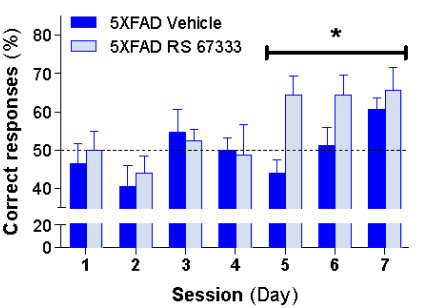

D

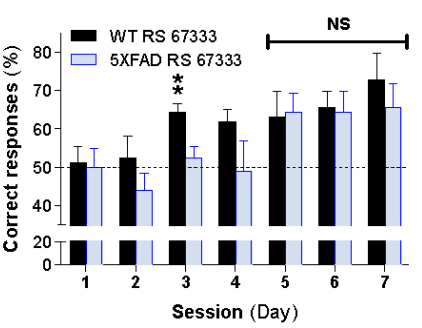

E

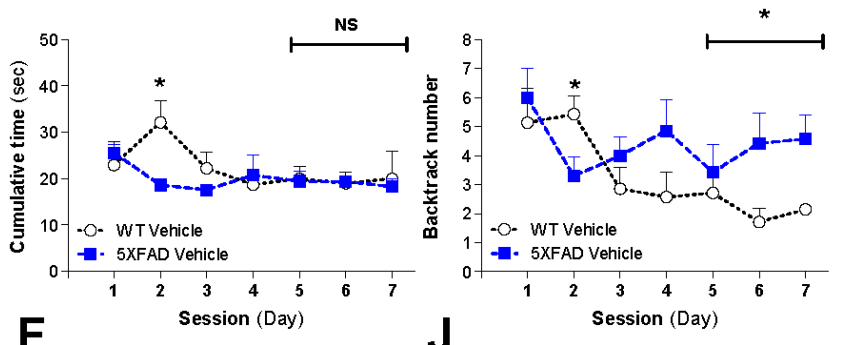

F

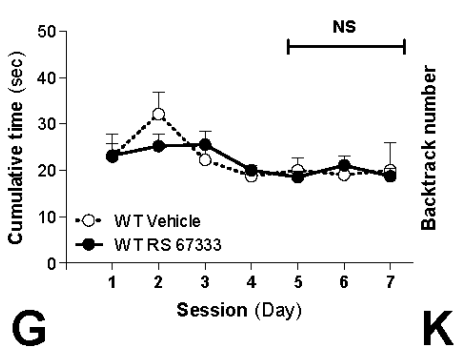
$2-O-W T$ Vehicle
$1-$ WT RS 67333
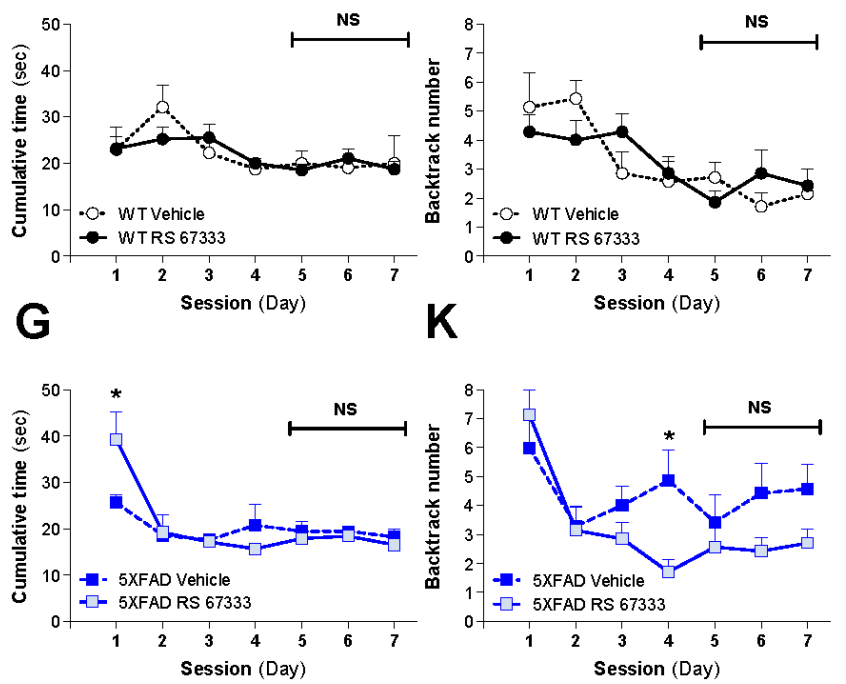

H

L
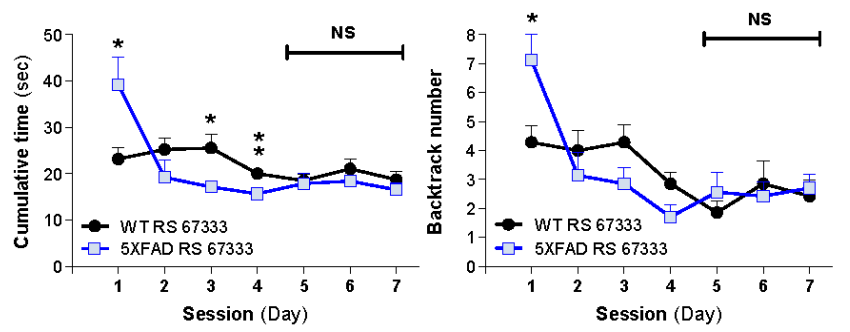

Figure 6 